九州大学学術情報リポジトリ

Kyushu University Institutional Repository

\title{
Bottom Sediments in Bays of North Kyushu
}

Mitsushio, Hiromi

Department of Geology, Kochi University

https://doi.org/10.5109/1543653

出版情報：九州大學理學部紀要：Series D, Geology. 18 (1)，pp.7-34，1967-02-15. Faculty of Science, Kyushu University バージョン :

権利関係 : 


\author{
Mem. Fac. Sci., Kyushu Univ., Ser. D, Geol., Vol. XVIII, No. 1, \\ pp. 7-34, 12 text-figs., Feb. 15, 1967
}

\title{
Bottom Sediments in Bays of North Kyushu
}

\author{
By
}

Hiromi Mitsushio

\begin{abstract}
The present paper contains the result of distributional and textural analyses of bottom sediments in several selected bays of North Kyushu which represent varying degrees of embayment from closed to opened one. Generally mud content in sediments is related with the embayment degree of bays; a bay with higher degree of embayment has more muddy sediments. Four sedimentary environments in relation to textural composition of bottom sediments are recognized: (1) bay-mouth environment with sandy sediments, (2) bay-centre environment with muddy ones in closed bays and with sandy ones in opened bays, (3) bay-head environment with muddy ones, and (4) coastal environment with gravelly ones and rocky bottom.

Textural composition of the sediments shows that the best sorting is within the medium-sand grade, both below and above this size grade the sorting becoming poorer, and that the maximum coarse skewness occurs in the grades of very coarse and fine sands whereas the minimum one in those of medium sand and coarse silt. This feature agrees well with the result of study of recent fluvial sediments by FoLK et al. (1957) and that of modern deep-sea sediments by HUBERT (1962) among others. It seems to be significant that the textural characteristics of the present sediments are similar both to those of fluvial sediments and to those of bathyal ones, even if they are recent or ancient.
\end{abstract}

\section{Introduction}

1. Purpose of study.-To study the bottom sediments in bays is important not only for sedimentology but also for marine geology, because the hydraulic and physiographic controls are effectively operative on the sediments there. In most bays the data of bottom sediments are readily obtainable and furthermore, biological and hydrographical data are sometimes available which are very important for better interpretation of the sedimentological data.

At the suggestion of Professor Tatsuro Matsumoto, therefore, the writer has been engaged in a study of the bottom sediments in some bays and adjacent offshores of North Kyushu. In the present work it is especially stressed to clarify the textural composition of sediments of bays and to compare the results between bays of different environments. The selected bays for this purpose are as follows:

Omura Bay: An example of an almost enclosed bay with an extremely narrow entrance

Manuscript received September 16, 1966

Hiromi Mirsushio: Department of Geology, Kochi University, Kochi [Formerly a post-graduate fellow at the Department of Geology, Kyushu University]. 
Sakitsu Bay: A long and narrow, much constricted bay with several inlets Fukuoka Bay: A half opened bay with a spit at the entrance, an island in the bay, and rivers and lowland on the back

Arikawa Bay: An opened bay of V-shaped outline

Usuki Bay: An opened bay of V-shaped outline, with an elongated valley on the back

Tsukumi Bay: Another V-shaped, opened bay, without large rivers and plains on the back

Karatsu Bay: An opened bay of W-shaped outline, with more rocky coasts, less developed coastal plains and smaller rivers than Fukuoka Bay

Chijiwa Bay: A widely opened, semi-circular bay, which, however, is somewhat special in that it has a submarine channel at one point

The descriptions in Chapter III do not follow the above order but are given according to the geographical position.

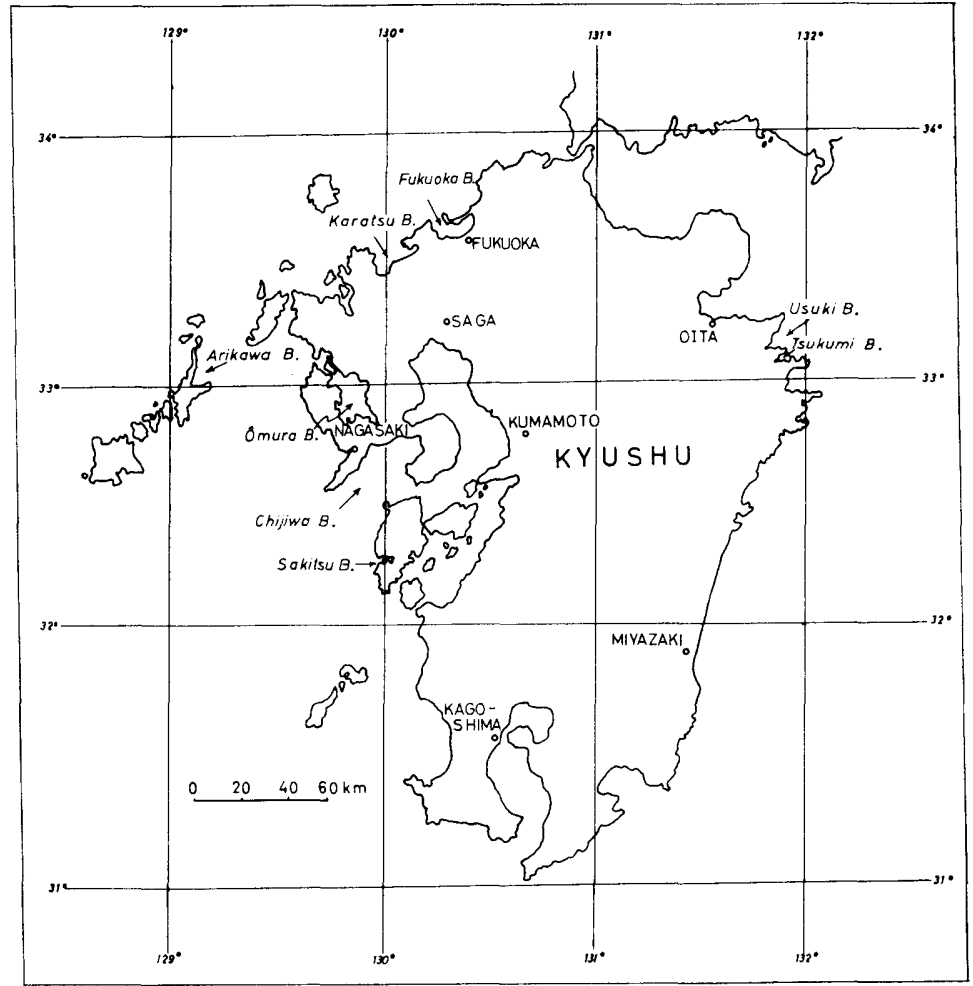

Fig. 1. Index map of surveyed sea-area.

2. Research history.-Researches on textural composition of bottom sediments on the shelf around Kyushu have been rather few. As early as 1932, YABE and TAYAMA described submarine topography near Ikino-shima Island and the western part of the main island of Kyushu, but did not mention so much on sediments. Twenty years later, Hoshino (1952), in his study of muddy sediments on the shelf of the Japanese Islands, showed an outline of distribution of mud around 
Kyushu. INOUÉ (1954) worked on a grain size distribution of bottom sediments in Omura Bay. In 1957 KAMATA briefly reported bottom sediments in Ariake Bay, while bottom topography of the northern part of the same bay was described by Hoshino (1958). Kamata (1959) further studied bottom sediments in Aba Cove of Chijiwa Bay. Kamata and HoRIGUCHI (1963) studied bottom sediments off Mogi, western part of the same bay, and KAMATA (1964) also worked on sediments in Nagasaki Port. Furthermore, Ariake Bay Research Group (1965) made a comprehensive study of the Quaternary System of the Ariake and Shiranuhi Bay areas and presented many sedimentological data especially on soft clay in Ariake Bay. A valuable contribution has been made by MATSUISHI (1966) to the distribution and sedimentation of iron-bearing sands in Ariake Bay. In addition to these works by various authors, bottom sediments in Karatsu Port, Tsukumi Port and Ushibuka Port were partly analysed by the Hydrographic Department, Japan Maritime Safety Board (1959).

In 1961 the writer began to study systematically bottom sediments around the main island of Kyushu. As the first result of his study he reported the submarine sediments near the Tomioka Headland, Amakusa (Mitsushio, 1964). Subsequently bottom sediments off the Itoshima Peninsula, west of Fukuoka City, and off Tsuyazaki, north of Fukuoka City, were described (MITsushio, 1965a and $\mathrm{b}$ ).

3. Acknowledgements.-The writer wishes to express his most sincere thanks to Professor Tatsuro MATsumoto of Kyushu University, who has supervised this study with constant encouragements and has critically read the manuscript. Special thanks are also due to Assistant Professor Tsugio SHuto of the same university, who has advised him in a proper way and helped him in some of his field surveys. Sincere appreciation is acknowledged to Dr. Hakuyu OKaDA, who has helped him in various ways and has critically read the first draft of this paper. Also he wishes to express his thanks to Professor Ryuzo ToRIYAMA and Assistant Professor Kametoshi KANMERA of the Kyushu University for their valuable suggestions. Thanks are also due to Dr. Itaru HAYAMI, Dr. Juichi YANAGIDA, and the other members of the same university for their kind assistance. Furthermore, he is indebted to Dr. Tadashige HABE and Ikuwo OBATA of National Science Museum of Japan, for their instructive help on biological side. Thanks are extended to Fukuoka, Nagasaki, and Oita Fisheries Experimental Stations for their kind offer of dredging facilities as well as supply of bottom samples. Miss Yûko WADA and Miss Tomoko MIYAZAKI have assisted the writer in drafting and type-writing.

This study is financially supported by the Ikueikai Scholarship, by the award granted from the Matsumoto Funds, partly by the award from the Takachiho Funds, and by the fellowship of the Japan Society for the Promotion of Sciences.

\section{Method}

1. Sampling.-Sampling has been made according to the predetermined design to cover effectively the surveyed sea-area with sampling stations at $2 \mathrm{~km}$ interval 
in Fukuoka Bay, Usuki Bay and Tsukumi Bay, at $300 \mathrm{~m}$ interval in Sakitsu Bay, and at about $3 \mathrm{~km}$ interval in Chijiwa Bay. For unavoidable reasons, sampling sites were randomly selected in Karatsu Bay, Omura Bay and Arikawa Bay. To locate dredging sites, charts prepared by the Hydrographic Department, Japan Maritime Safety Board, are used. Sampling locations and their geographical positions in the surveyed areas are indicated in the maps of Chapter III.

A simple dredger and the dredgers of Niino-, Eckman-, and S.K.-types were used for sampling. Although a dredger of one and the same type should be used in all the cases, actually it is almost impossible to do so owing to difference in sea-bottom conditions, facilities of boats, availability of assistants and so on. Unlikely effects perhaps caused by using dredgers of different types, however, are quantitatively negligible. Samples for examination were taken from the innermost portion of materials caught in a dredger, because it seems to preserve material in the original state of composition than the outer portions.

Dredging in Karatsu Bay was undertaken by Fukuoka Fisheries Experimental Station, in Omura Bay and Arikawa Bay by Nagasaki Fisheries Experimental Station, and in Tsukumi Bay by Oita Fisheries Experimental Station. Bottom sediments in the other bays were dredged by the writer with assistance of workmen.

2. Mechanical analysis.-Various methods have been devised for mechanical grain analysis of sediments (TWENHOFEL and TYLER, 1941; NASU and SATO, 1957; etc.). For gravel and sand, the sieving method by the use of screens with openings according to WENTWORTH's grade scale, is a standard way, and for mud the pipette method is applied.

The writer used seven standard sieves of $20 \mathrm{~cm}$ in diameter, authorized by the Japanese Industrial Standard. They are 5, 9, 16, 32, 60, 115 and 250 meshes, which are arranged on the WeNTwoRTH's grade scale: 4, 2, 1, 1/2,1/4, 1/8 and $1 / 16 \mathrm{~mm}$ in openings of screens, respectively. For sieving the writer used a Ro-Tap automatic shaking machine. At first, he attempted to check adequate volume of a sample and adequate time of shaking for the Ro-Tap sieving. For this purpose, he used a standard sample of sand with the following texture: $\operatorname{Md} \phi 1.00, \mathrm{M} \phi 1.00$, $\sigma \phi 2.68, \alpha \phi 0$ (statistical parameters of grain size should be referred to those in the next article Analysis of data.). The result of this preliminary examination is summarized in the following table:

$\begin{array}{ccccc}\text { minute } & \mathrm{Md} \phi & \mathrm{M} \phi & \sigma \phi & \alpha \phi \\ 5 & 1.01 & 0.95 & 2.63 & -0.02 \\ 10 & 1.01 & 0.99 & 2.64 & -0.01 \\ 15 & 1.02 & 0.97 & 2.64 & -0.02\end{array}$

Values of $\mathrm{Md} \phi, \mathrm{M} \phi, \sigma \phi$, and $\alpha \phi$ obtained by 10 -minute sieving are the nearest to those of the original sample. Thus $\mathbf{1 0}$ minutes seem to be enough time for the Ro-Tap shaking. TwENHOFEL and TYLER (1941) also obtained similar results.

As to volume of a sample, Twenhofel and TYLer (1941) and NASU (1956) took 40-50 gr. as an adequate volume for analysis. In this study the writer used samples of $100 \mathrm{gr}$., because the loss percentage during operation is easily chequed. For mud the pipette method is used, which is the most customary way 
(Krumbein and PetTiJohn, 1938; Nasu, 1956). Mixture of sand and mud is divided into each grade by means of wet sieving through 250 meshes.

3. Analysis of data.-For quantitative comparison of size-analysis data, some statistical methods have been proposed: Trask's quatile method (1932), INMAN's phi-moment method (1952) and FolK's method (FoLK and WARD, 1957). The writer adopts INMAN's method in this paper, because the parameters for grain size statistics are easily obtainable from graphs, the calculation is simple, and the results obtained are precisely comparable with each other. Of the statistical parameters prepared by INMAN, the following four are used in this study:

$$
\begin{aligned}
& \mathrm{Md} \phi=\phi_{50} \\
& \mathrm{M} \phi=\left(\phi_{16}+\phi_{84}\right) / 2 \\
& \sigma \phi=\left(\phi_{84}-\phi_{16}\right) / 2 \\
& \alpha \phi=(\mathbf{M} \phi-\mathbf{M} d \phi) / \sigma \phi
\end{aligned}
$$

where $\mathbf{M d} \phi$ : median diameter in phi-scale, $\mathbf{M} \phi$ : mean diameter in phi-scale, $\sigma \phi$ : sorting coefficient in phi-scale, $\alpha \phi$ : skewness in phi-scale.

The parameters with a phi-symbol are obtainable in the phi-scale devised by KRUMBEIN (1934), which is constructed from a logarithmic transformation equation to the Wentworth's grade scale: $\phi=-\log d / \log 2$. Here $d$ is the measured diameter of a grain in millimeter.

\section{Description}

\section{A. Fukuoka Bay}

1. Geographical position.--Fukuoka Bay in north Kyushu (Fig. 1) is embraced on the northern side by a long, narrow sand spit called Umi-no-nakamichi, with which the bay is separated from the sea of Genkai-nada. Its approximate position is lat. $33^{\circ} 40^{\prime} \mathrm{N}$ and long. $130^{\circ} 20^{\prime} \mathrm{E}$.

2. Geomorphological feature.-At the western tip of the spit Shikano-shima Island is tied up with Umi-no-nakamichi and results in a land-tied island. The neck portion between Shikano-shima Island and Umi-no-nakamichi is drowned at high tide. Well-sorted sand dune and beach are well developed from the neck eastwards, for the distance of about $11 \mathrm{~km}$.

Fukuoka Bay is divided into three parts by Noko-no-shima Island, namely, the bay mouth, through which the bay is connected with the Genkai-nada Sea, Imazu Cove and Hakata Port. This division is geographically natural. Imazu Cove is also characterized by the development of a sand spit and a lagoon (Fig. 3a). The estuary of the Zuibaiji is here called Zuibaiji lagoon on account of topography. To the north of the lagoon a sand spit is developed, which is called Imazu spit in this paper. On the hinterland of this bay a wide plain is developed where large and small rivers are running into the bay.

Submarine topography is shown in Fig. 3a. The depth of the bay mouth is about $17 \mathrm{~m}$. The central part of the area attains the depth of $20 \mathrm{~m}$, and forms a small basin-like depression. Imazu Cove is $10 \mathrm{~m}$ in the deepest part. Hakata port occupies the wide area of the eastern part of Fukuoka Bay. The port area 


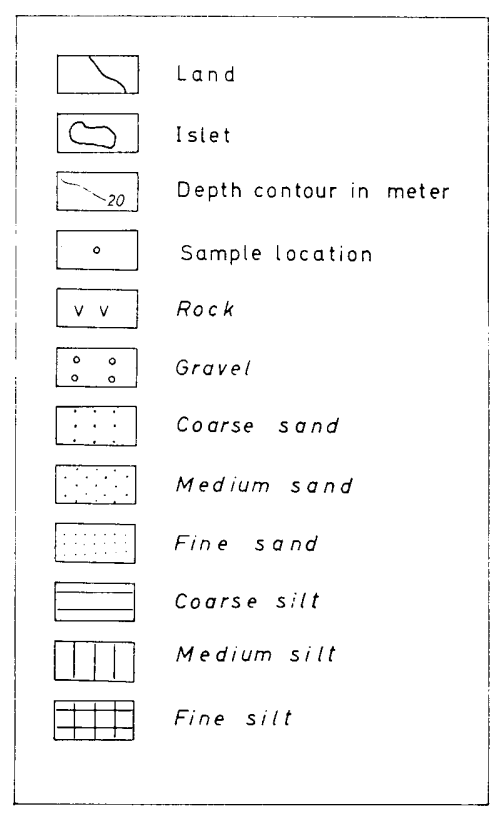

Fig. 2. Index figure.

This index should be referred to all figures illustrated in this text.

is characterized by broad submarine flat or terrace at the depth of 5-10 m. The constant current in Fukuoka Bay is about 0.1 knot in velocity.

3. Sample location.-The samples were collected by Fukuoka Fisheries Experimental Station. Locations of sampling are shown in Fig. 3a.

4. Bottom sediment.-The distribution of bottom sediments is shown in Fig. 3b. Silt is the finest sediment in the surveyed area. It is distributed east of Nokonoshima Island, in the central part of Hakata Port, off Gannosu on Umi-nonakamichi spit and off the Naka-gawa River. It is also found in the innermost part of Hakata Port. Coarse silt covers bottom areas off the estuary of the Tatara River, off Saitozaki on Umi-no-nakamichi spit, an area between Shikano-shima Island and Nishi-koén (West Park) of Fukuoka and north of Shikano-shima Island. The constant current with velocity of about 0.1 knot in Hakata Port may be responsible for the deposition of muddy sediments.

Fine sand is distributed in Imazu Cove, off Imazu spit and in the area between Shikano-shima Island and Nishino-ura Cape of the Itoshima Peninsula. It is also distributed near the shore except for one locality of Station 26. Coarse sand is distributed east of the Itoshima Peninsula, west of Nokono-shima Island and southwest of Shikano-shima Island. It is also found near the shore. Gravel is found in a few places; near Imazu Cove and off the eastern and western coast of Nokono-shima Island. Rocky bottom is exposed near Nokono-shima Island and in some places off the coast of adjacent land. 


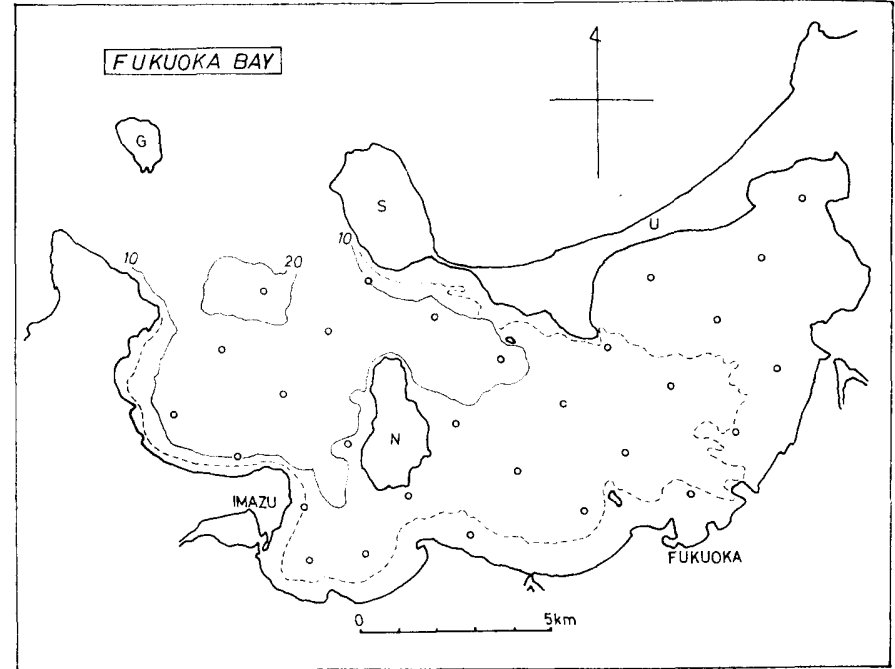

Fig. 3a. Sample locations and depth contours in Fukuoka Bay. $\mathrm{U}$ : the Umino-nakamichi Peninsula; S: Shikano-shima lsland; N: Nokono-shima Island

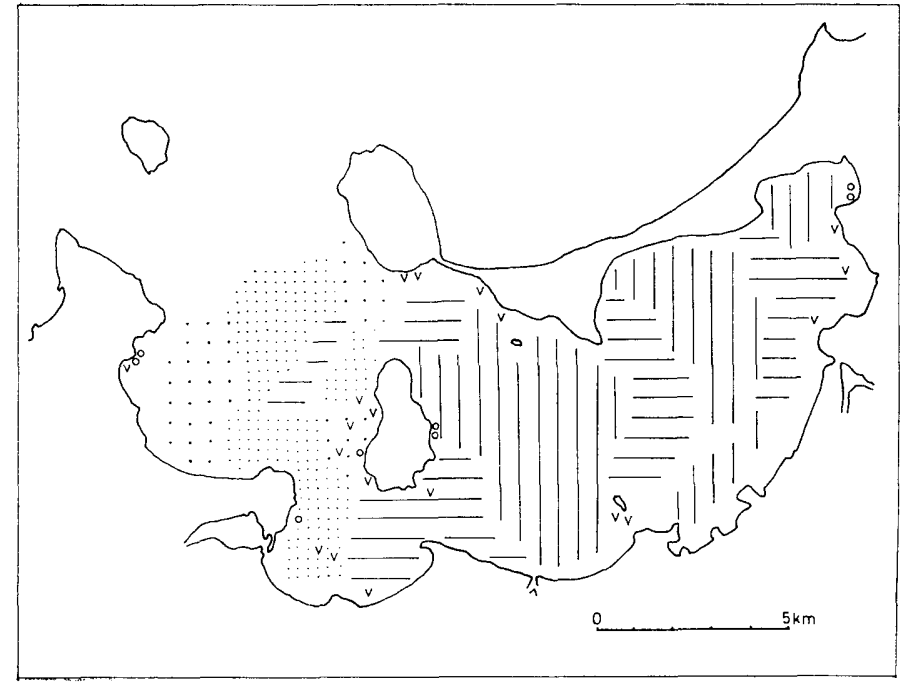

Fig. 3b. Distribution of bottom sediments in Fukuoka Bay.

\section{B. Karatsu Bay}

1. Geographical position.-Karatsu Bay is situated to the west of Fukuoka and faces to the Genkai-nada Sea. Its approximate position is lat. $33^{\circ} 30^{\prime} \mathrm{N}$ and long. $130^{\circ} \mathrm{E}$ (Fig. 1).

2. Geomorphological feature.-Karatsu Bay consists physiographically six parts, namely, Hikitsu-ura Cove, Kamuri Port, Fukaé Port, Matsuura-gata, Karatsu Port (Tsubusa Cove) and the main part of Karatsu Bay from east to west. The 
outer limit of the bay is defined by a line drawn from Hotoke-saki of the westernmost tip of the Ito-shima Peninsula to Minato, north of Karatsu City, through Hime-shima and Kashiwa-jima Islands. The depth of the bay mouth is about $30 \mathrm{~m}$ between Hime-shima and Kashiwa-jima Islands.

Karatsu Bay is studded with many islands and islets: Hime-shima Island, Kashiwa-jima Island, Oshima Island, Taka-shima Island, Tori-shima Islet, and Ha-shima Islet. Among them, Oshima Island is a land-tied island. Shigino-kubi of the southwestern part of the Itoshima Peninsula also displays a kind of a land-tied island, separating Kamuri Port from Hikitsu-ura Cove on the eastern side of Karatsu Bay, where the depth is about $10 \mathrm{~m}$.

Fukae Cove is embraced by the two capes of Osaki and Haisaki and its depth contour begins to foreshadow embayment at $9 \mathrm{~m}$. Matsuura Bight, which is defined by a line drawn from Oshima Island to Kushizaki Cape, is $10 \mathrm{~m}$ or more deep at the bay mouth. Karafusa Cove, which lies between Karafusa and Oshima, northwest of Karatsu City, is about $10 \mathrm{~m}$ deep at the bay mouth. Hikitsu-ura Cove, Kamuri Port and Matsuura Bight are shallower than $10 \mathrm{~m}$.

The eastern part of Karatsu Bay near two coves of Fukaé and Kamuri, however, is not so simple in submarine topography. The depth contours in the area between Kamuri Port and nearly $10 \mathrm{~km}$ west of the port show a valley-like depression which is just a seaward extension of the Izumi River. This was probably a valley when the sea-level was lower. Therefore, the writer calls this submarine valley the Paleo-Izumi River. It seems to come to end at the depth of approximately $25 \mathrm{~m}$. The Matsuura River, whose estuary is bent abruptly

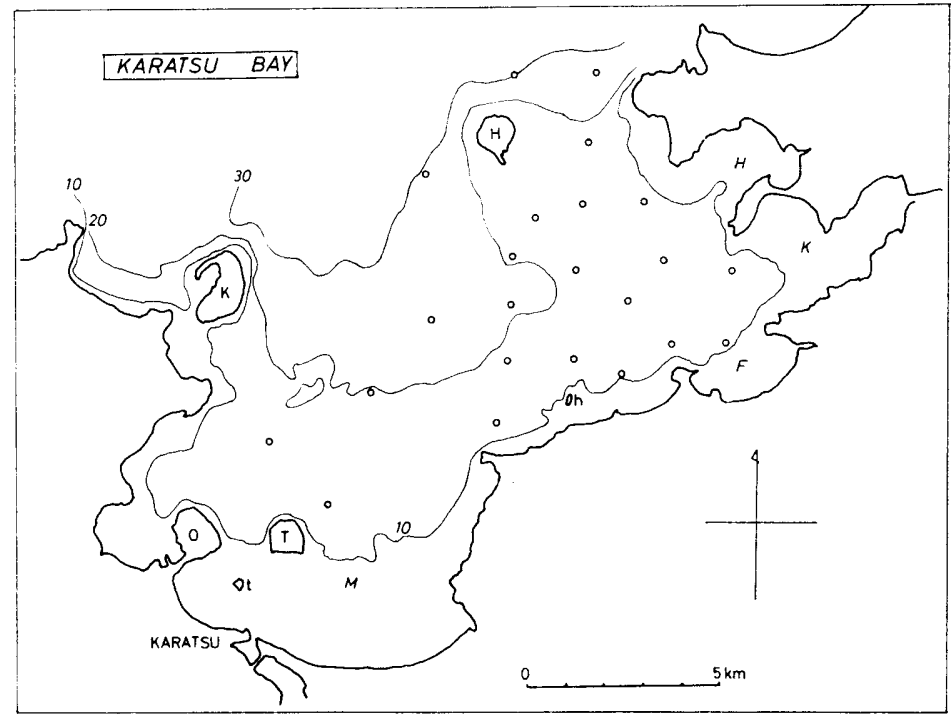

Fig. 4a. Sample locations and depth contours in Karatsu Bay. $\mathrm{H}$ : Hime-shima Island; $\mathrm{K}$ : Kashiwa-jima lsland; $\mathrm{T}$ : Taka-shima Island; $\mathrm{O}$ : Oshima Island; $\mathrm{t}$ : Tori-shima Islet; $\mathrm{h}$ : Hashima Islet; H: Hikitsu Cove; K: Kamuri Port; F: Fukaé Port; M: Matsuuragata Bight 


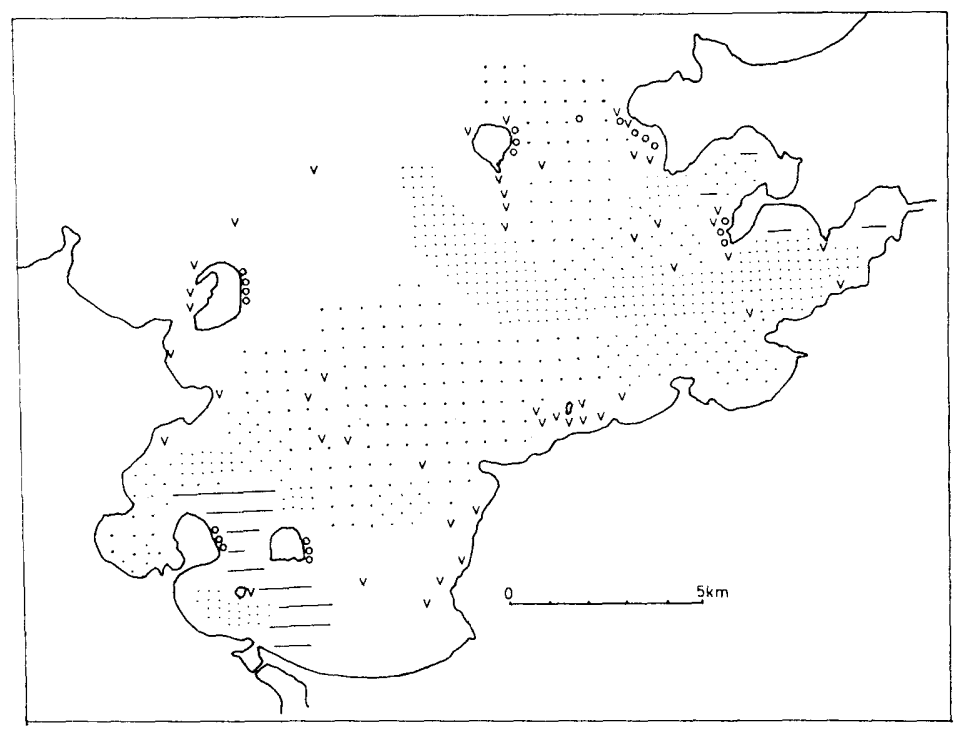

Fig. 4b. Distribution of bottom sediments in Karatsu Bay.

westward, causes no remarkable effect on submarine topography.

3. Material.-The sample locations are shown in Fig. 4a. Collection of samples from the main part of the bay and mechanical analysis of them were undertaken by Fukuoka Fisheries Experimental Station. These data have been supplied by the courtesy of this Station for the writer's reexamination. The data by the Hydrographic Department for Matura-ura and those by the writer himself for Hikitsu and Kamuri Coves have been added to them.

4. Bottom sediment.-Fig. $4 \mathrm{~b}$ shows the distribution of the bottom sediments in Karatsu Bay, which are characterized by various grades of sands. Coarse sand is distributed near Hime-shima Island and in the main part of Karatsu Bay. Fine sand is found in the Paleo-Izumi River, presenting a narrow band, and at a locality about $1 \mathrm{~km}$ southwest of Hime-shima Island. Fine sand is well sorted except for that from Station 16, which is adjacent to coarse sand. Fine sand is always negatively-skewed. Medium sand occupies the western part of Karatsu Bay, Hikitsu-ura Cove and Fukaé Port. In the western part of the bay, however, coarse to fine sands present stripe pattern. The textural variation of coarse to fine sands is shown on Table 1 and in Figs. 11 and 12.

Muddy sediments are distributed mainly near the Karatsu Port and subordinately in Hikitsu and Kamuri Coves. They are mainly composed of coarse silt. Rocky bottoms are detected around Hime-shima Island, and west of Kashiwa-jima Island, in the eastern part of Matsuura Bight, at Hotoke-saki and Shigino-kubi of the Itoshima Peninsula and around Hashima Islet that lies between two heads of Hai-saki and Kushi-saki. Gravel, another minor component, is seen near islands and headlands. 


\section{Omura Bay}

1. Geographical position.-Omura Bay is situated at the northwestern part of Kyushu. The approximate position of its center is lat. $33^{\circ} 00^{\prime} \mathrm{N}$ and long. $129^{\circ} 51^{\prime}$ E (Fig. 1).

2. Geomorphological feature.-Omura Bay is embraced by Hario-shima Island and the Nishi-sonoki Peninsula, which separate the bay from the Sumo-nada Sea. More than 27 islets are scattered in the bay, which is also fringed with a number of inlets. Depth contours are shown in Fig. 5a. The deepest place, measuring $30 \mathrm{~m}$ or more, is about $500 \mathrm{~m}$ southeast of the Hario-seto Straits. The $20 \mathrm{~m}$ depth contour runs meridionally off the eastern coast of the Nishi-sonoki Peninsula. The main part of the bay is shallower than $18 \mathrm{~m}$. Tidal currents flow through the Hario-seto Straits into Omura Bay (see SHUTo, 1953).

3. Sampling.-The examined samples from Omura Bay were dredged and collected by the officers of Nagasaki Fisheries Experimental Station. Their locations are shown in Fig. 5a. Samples were mechanically analysed by INOUÉ (1954). The writer recalculated INOUE's data by the method of INMAN (1952).

4. Bottom sediment.-The distribution of bottom sediments is shown in Fig. 5b. A rocky bottom is exposed near the Hario-seto Straits, being distributed in parallel with both the depth contour of $30 \mathrm{~m}$ and the flow direction of tidal currents. Although gravel is reported at some localities on the hydrographical chart, its distribution is so restricted that it is not indicated in Fig. 5b.

Coarse sand is not found in Omura Bay. Medium sand is sporadically distri-

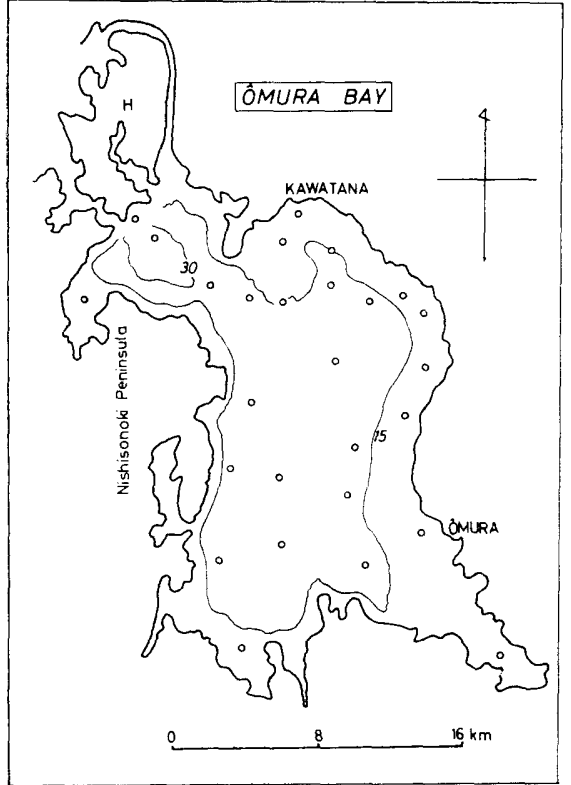

Fig. 5a. Sample locations and depth contours in Omura Bay. $\mathrm{H}$ : Hario-shima Island

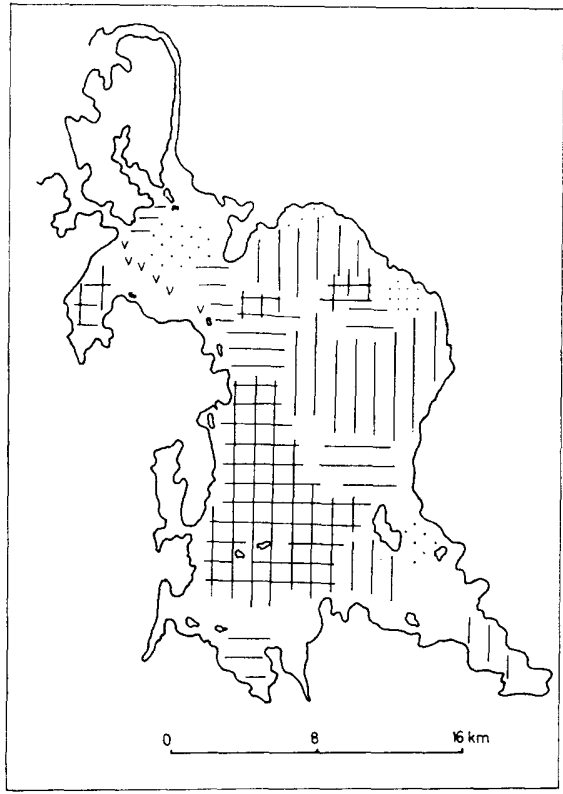

Fig. 5b. Distribution of bottom sediments in Omura Bay. 
buted near Hario-shima Island, off Kawatana and Omura Port. Fine sand is found only at one locality in the eastern part of Omura Bay.

Coarse silt is distributed to the north of Mishima Islet off Omura Port, between Osaki Head and Miyano-ura Port, and in a few other small areas. The first two of these areas are parallel to the direction of tidal currents and situated between the rocky bottom and the area of medium or fine silt. Medium silt is mainly distributed in the eastern central part of Omura Bay and off Kawatana. It is also found in Tsumizu Cove at the southeastern corner of the bay. Fine silt is distributed in the western main part of Omura Bay, in Ogushi Cove and off Kawatana. The textural variation of these sediments is shown in Fig. 12 and on Table 1.

To sum up, the bottom sediments in Omura Bay are characterized by the predominance of mud.

\section{Arikawa Bay}

1. Geographical position.-Arikawa Bay is the largest of numerous small bays of Nakadori-shima Island, northeastern main island of the Goto Archipelagoes, Nagasaki Prefecture. It is located at lat. $33^{\circ} \mathrm{N}$ and long. $129^{\circ} 10^{\prime} \mathrm{E}$ (Fig. 1).

2. Geomorphological feature.-Arikawa Bay presents a trumpet-like form, which opens northeastward. Thus, in the bay-form it is very similar to Usuki Bay. The surveyed area is restricted to the western bay mouth of Arikawa Bay, off Ogushi of the middle part of Nakadori-shima Island. Depth contours are shown in Fig. 6a. A noteworthy fact is that the bottom slightly deeper than $40 \mathrm{~m}$ is roughly flat. Near the coast, however, the sea is rapidly deepened down to the depth of $30 \mathrm{~m}$.

3. Sampling.-Samples were collected according to a grid system of $300 \mathrm{~m}$ interval by the officers of Nagasaki Fisheries Experimental Station (Fig. 6a).

4. Bottom sediment.-The distribution of the bottom sediments is shown in

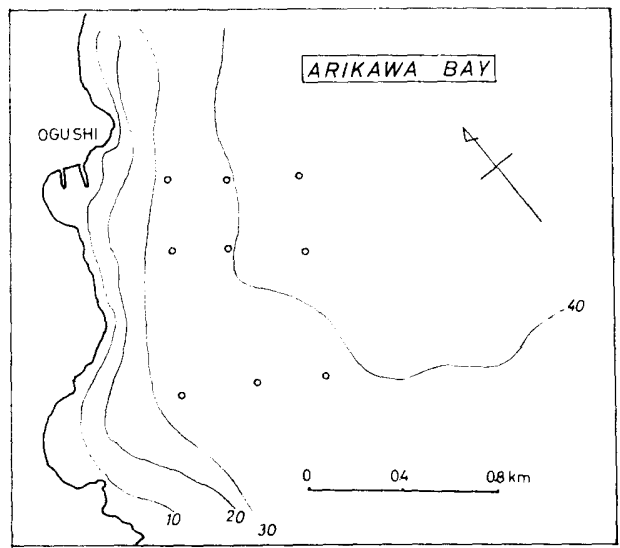

Fig. 6a. Sample locations and depth contours in the western part of Arikawa Bay.

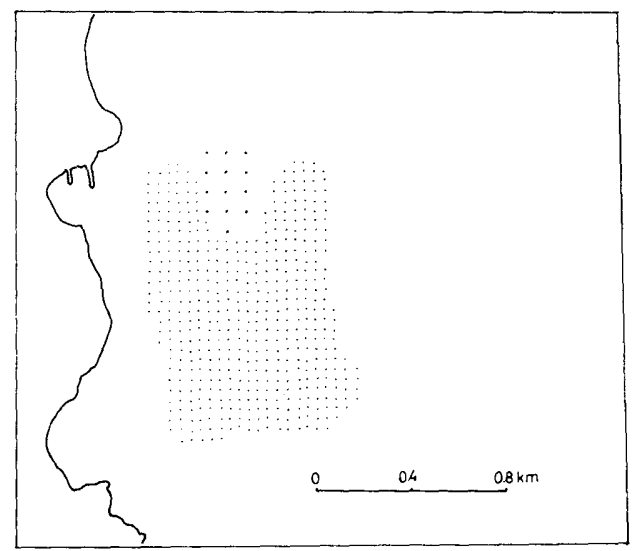

Fig. 6b. Distribution of bottom sediments in the western part of Arikawa Bay. 
Fig. 6b. There is neither rocky bottom nor gravel in the surveyed area. Coarse sand was detected only at Station 1 but medium sand has not yet been found. Fine sand is the main sediment in the surveyed area. The textural variations of the sediments are shown in Table 1.

\section{E. Sakitsu Bay}

1. Geographical position.- Sakitsu Bay is situated on the western side of Shimoshima, Amakusa, Kumamoto Prefecture. Its approximate location is lat. $32^{\circ} 20^{\prime} \mathrm{N}$ and long. $130^{\circ} \mathrm{E}$ (Fig. 1). It is the longest bay of the Amakusa Islands, presenting a key-like form (Fig. 7a). It is sometimes called Yokaku-wan, or otherwise. The name of Sakitsu Bay, however, seems to refer most properly to the present embayment.

2. Geomorphological feature.-Sakitsu Bay is fringed with a number of coves and islets, displaying a ria coast-a shoreline of submergence. They are, for instance, Hayaura and Kameura Coves on the southern coast and Oé-ura Cove, Ikusaga-ura Inlet and Sakitsu Cove on the northern coast. The Itchoda River is the largest of rivers and streams that flow into the bay. The Itchoda flows into Hayaura Cove, together with the Rogi stream. The coast is characterized by cliffs facing the sea of Amakusa-nada, without beach.

Several islets are dotted in Sakitsu Bay, for instance, Take-shima off the river mouth of the Itchoda, Miyaga-shima off the mouth of the Rogi stream, Koshima in Sakitsu Cove and Naka-shima Islet in Kameno-ura Cove. The sub-

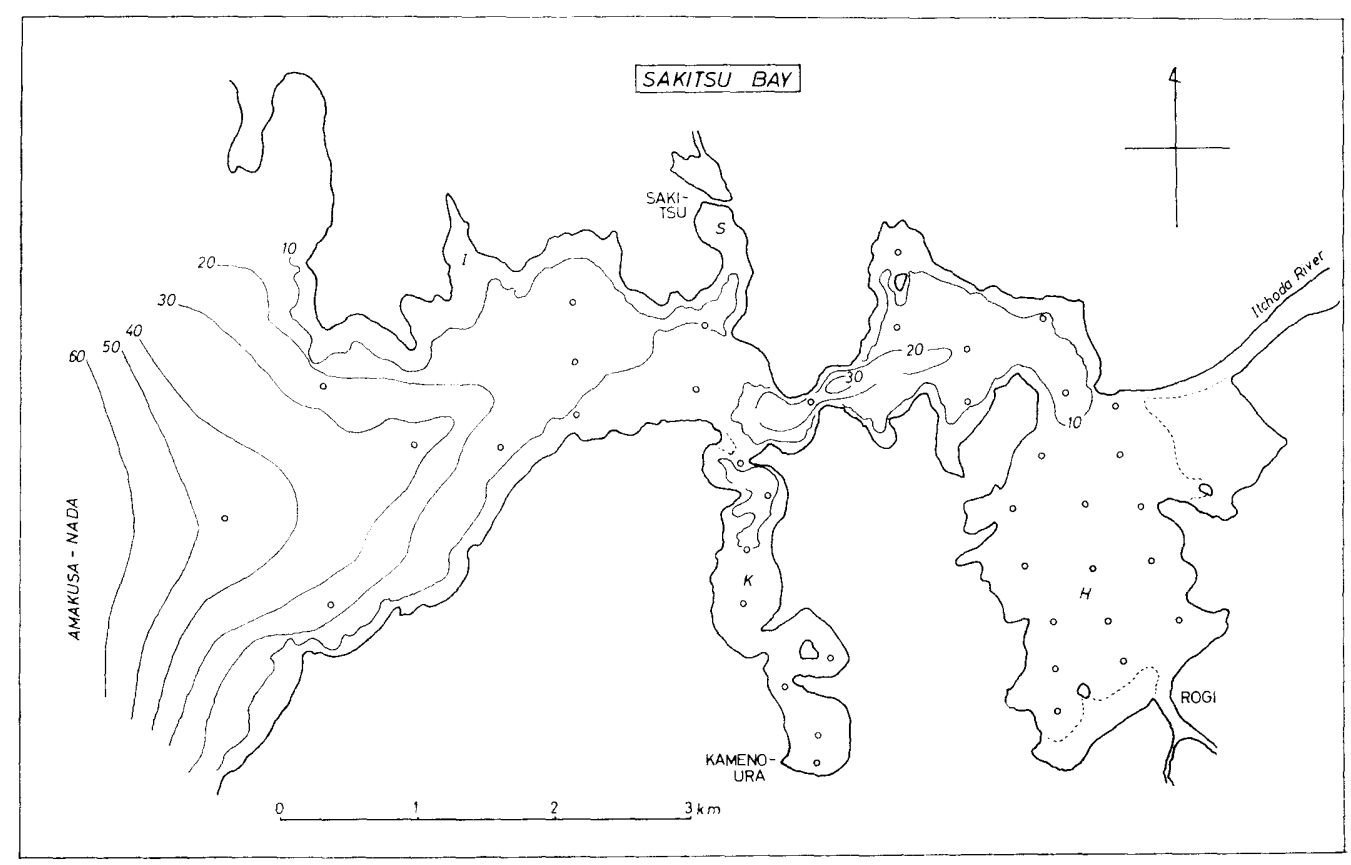

Fig. 7a. Sample locations and depth contours in Sakitsu Bay.

I: Ikusagaura; S: Sakitsu Port; K: Kameno-ura Cove; H: Haya-ura Cove. 


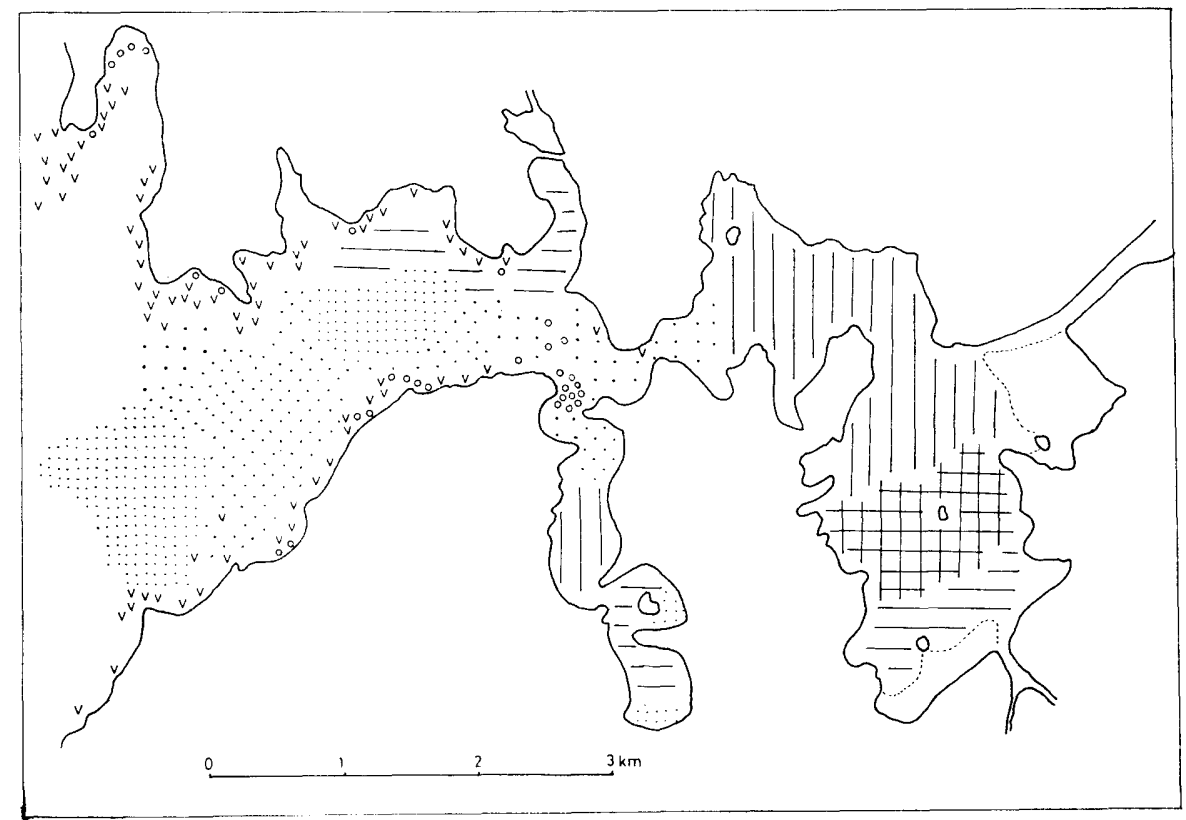

Fig. 7b. Distribution of bottom sediments in Sakitsu Bay.

marine topography in Sakitsu Bay is rather complicated. Hayano-ura Cove, eastern part of Sakitsu Bay, is shallower than $10 \mathrm{~m}$. Kameno-ura Cove is also shallower than $10 \mathrm{~m}$ except for the mouth, where depth attains $20 \mathrm{~m}$ or more and forms a caldron. An elongated caldron is also found just at the bay, adjacent to the mouth of Kameno-ura Cove. This train of caldrons topographically divides the bay into two parts: eastern and western. The former is at most $20 \mathrm{~m}$ deep, whereas the latter increases in depth westwards until $50 \mathrm{~m}$, forming a submarine valley. The contour of $60 \mathrm{~m}$ depth shows no embaymental form.

3. Sample location.--Sample locations in Sakitsu Bay are shown in Fig. 7a. The samples were dredged and collected on a $300 \mathrm{~m}$ grid chart by a team of Messers. T. Kikuchi, A. Taki, H. Otsuka, S. Kawaguchi, A. Kawaguchi, T. Goto, T. SAMEshima, a fisherman and the writer. The Oshima-maru, a survey vessel of Amakusa Marine Biological Laboratory and a small fishery boat were used for dredging. Seawater temperature near the surface was also measured at each dredging point.

4. Bottom sediment.-Fig. $7 \mathrm{~b}$ shows the distribution of bottom sediments. Although rocky bottoms are described on the chart near the coast of the western Sakitsu Bay, such a bottom has been met with only at Station 17. Gravel is distributed at the mouth of Kameno-ura Cove and near the coast of the western part of the bay.

Coarse sand is distributed just at the neck portion or central part of the bay mouth. Medium sand is distributed mainly at the bay mouth and at the mouth of Kameno-ura Cove. Fine sand is distributed at the bay mouth, in the central western part of the bay and in the inner part of Kameno-ura Cove. The 
variation of the textural composition of coarse to fine sand is shown on Table 1 and in Fig. 12.

Coarse silt is separately found in three places: Sakitsu Cove, the inner part of Kameno-ura Cove and the innermost part of Hayano-ura Cove. Medium silt is distributed mainly in the inner part of Sakitsu Bay and in the central part of Kameno-ura Cove. Fine silt is distributed only at the center of Hayano-ura Cove. The textural variation of muddy sediments is also shown on Table 1.

\section{F. Chijiwa Bay}

1. Geographical position.-Chijiwa Bay which is sometimes called Tachibana Bay, is located to the east of Nagasaki, West Kyushu, with its center approximately at lat. $32^{\circ} 40^{\prime} \mathrm{N}$ and long. $130^{\circ} \mathrm{E}$ (Fig. 1). It is connected with the Sea of Amakusa-nada to the south.

2. Geomorphological feature.-This bay is bordered by the Nomo Peninsula to the west and by the Shimabara Peninsula to the east. A channel called the Hayasaki Straits lies between the Shimabara Peninsula and Amakusa-shimoshima Island and ties up Chijiwa Bay with Ariake Inland Sea. Some islands are dotted near the coast. A number of inlets complicate the coast-line; they are Wakimisaki Port at the southern tip of the Nomo Peninsula, Mogi Port and Aba Cove near the joint of the peninsula and Obama Port of the Shimabara Peninsula.

The constant current in Chijiwa Bay, as measured in the eastern part of the bay by Nagasaki Marine Meteorological Observatory (1954), circulates counterclockwise in the bay. An interesting fact is that the current flows with velocity of about 0.9 knot into Ariake Inland Sea through the Hayasaki Straits on the Amakusa side and flows out on the Shimabara side with the same velocity.

A characteristic feature in the submarine topography is that submarine terraces are developed at the depth of 35 to $40 \mathrm{~m}$ in the northern part of the bay and at the depth of $60 \mathrm{~m}$ at the bay mouth. A submarine valley is traced along the eastern coast of the Nomo Peninsula at the depth of 30 to $60 \mathrm{~m}$. The submarine topography near and in the Hayasaki Straits is complicated by caldrons with a NWW-SEE trend. The deepest point in one of the caldrons is $159 \mathrm{~m}$ deep according to the chart. It decreases in depth until $154 \mathrm{~m}$ in the Ariake Inland Sea (Ariake Bay Research Group, 1965).

3. Sample location.-The locations of samples collected in Chijiwa Bay are shown in Fig. 8a. Grid sampling was carried out at about $3 \mathrm{~km}$ interval.

4. Bottom sediment.-The distribution of bottom sediments in Chijiwa Bay is shown in Fig. 8b. Rocky bottom on a small scale is found near the Hayasaki Straits (Maritime Safety Board, 1959) and off the Tomioka Headland (MITsushio, 1964), although it is not indicated in Fig. 8 b.

Gravel is distributed off the Tomioka Headland, being usually accompanied by coarse sand. Coarse sand at the central northern part of the bay, therefore, is rather unusual in distribution. Medium sand is sporadically distributed in Tomioka Bight of Amakusa-shimoshima Island and west of the Shimabara Peninsula. Fine sand is most widely distributed in the northwestern part of Chijiwa 


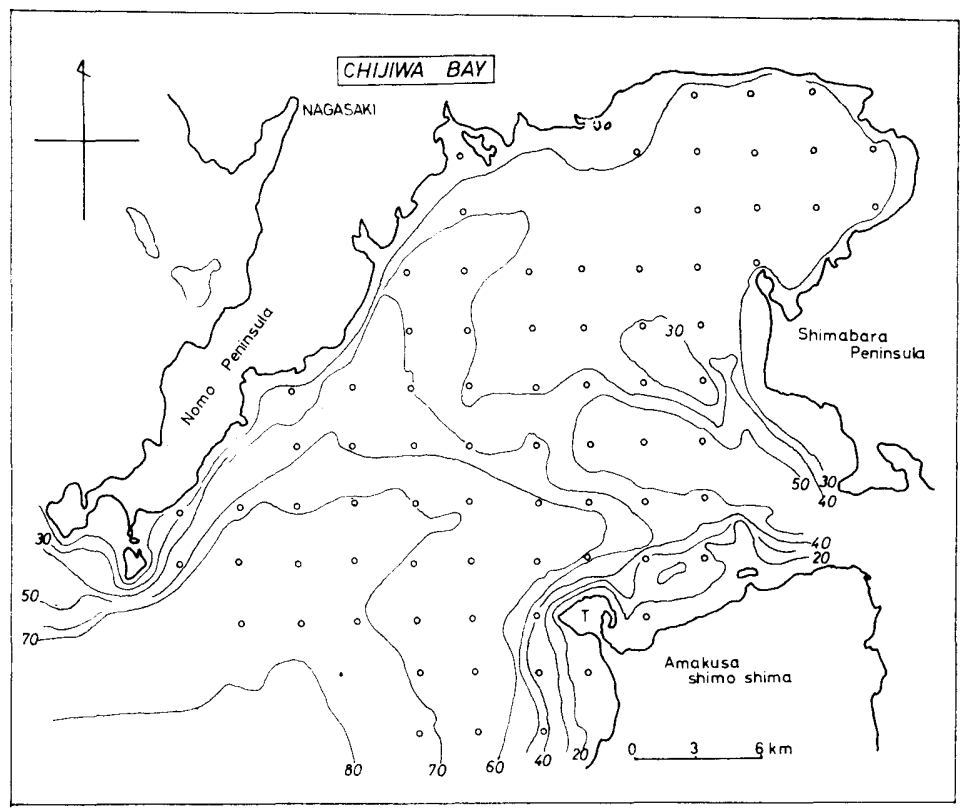

Fig. 8a. Sample locations and depth contours in Chijiwa Bay. $\mathrm{T}$ : the Tomioka Headland

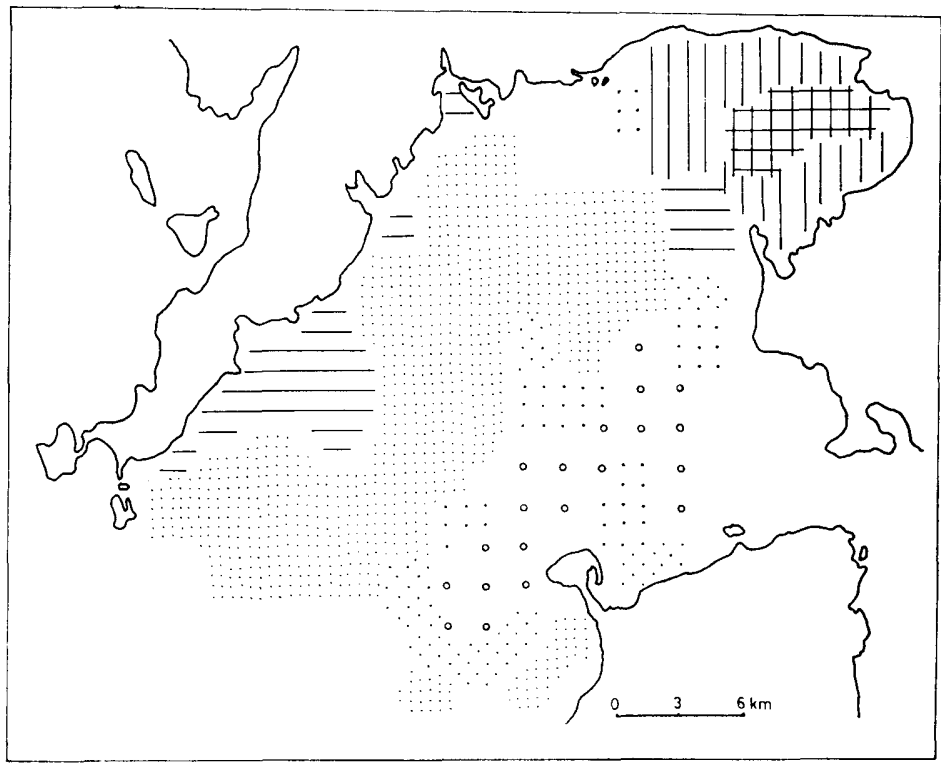

Fig. 8b. Distribution of bottom sediments in Chijiwa Bay.

Bay and between the Nomo Peninsula, off Mogi Port, Aba Cove and off the west coast of the Shimabara Peninsula. Medium and fine silts are distributed in the northeastern part of Chijiwa Bay, where fine silt area is enclosed by coarse silt. 
G. Usuki Bay

1. Geographical position.-Usuki Bay is situated in Oita Prefecture on the eastern side of middle Kyushu. Its approximate location is lat. $33^{\circ} 10^{\prime} \mathrm{N}$ and long. $130^{\circ} 50^{\prime} \mathrm{E}$ (Fig. 1). The bay opens to the Bungo Straits between eastern Kyushu and western Shikoku. It is bordered on its north side by the Sagano-seki Peninsula, which is facing to the head of Sadano-misaki, with a narrow channel called Hayasui-seto (or Hoyo Straits) between them.

2. Geomorphological feature.-Usuki Bay is V-shaped in outline, consisting a part of the ria coasts on both sides of the Bungo Straits. In it are scattered several small islands, for instance, Tsukami-shima, Kuro-shima, Mitsugo-shima, Tsuta-shima, and Muku-shima Islands (Jimuku-shima and Okimuku-shima).

According to Matsumoto et al. (1963), the Saganoseki Peninsula to the north consists mainly of schists and serpentinites and partly of the Cretaceous Onogawa Group. The headland to the south is made up of Upper Paleozoic strata. There is a fault-line valley of NE-SW trend, which is now embedded with the Aso welded tuff and the Alluvium. The Usuki River running along this valley flows into the bay.

A sand beach is not well developed, but rocky beaches are found in many places. Stocks made by wave erosion are also seen near Kuro-shima Islet. A plan view of Usuki Bay presents almost an equilateral triangle with three poles at Usuki, Saganoseki and Muku-shima (Fig.9a). Usuki City is located at an apex of the triangle, the base of which is characterized by a row of submarine uplifts and islets running from Saganoseki to the southeast. Outside it an

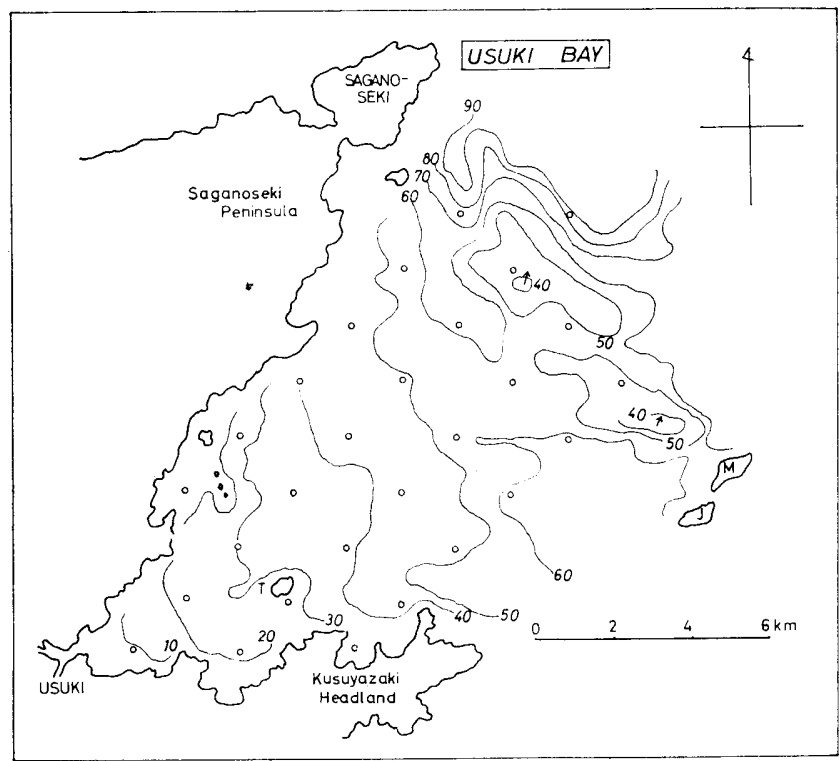

Fig. 9a. Sample locations and depth contours in Usuki Bay. $\mathrm{T}$ : Tsukumi Island; $\mathrm{M}$ : Muku-shima Island; $\mathrm{J}$ : Jimuku-shima Island 


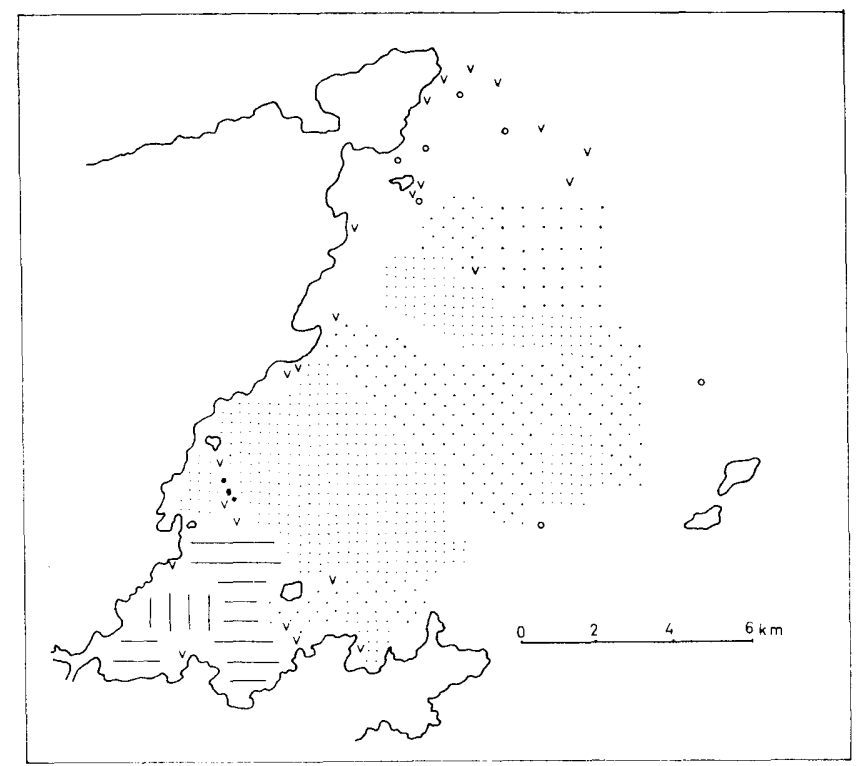

Fig. 9b. Distribution of bottom sediments in Usuki Bay.

elongated depression deeper than $100 \mathrm{~m}$ runs in NW-SE trend. The same direction is also taken by the depressed zone or a train of caldrons of Hayasui-seto (SHEPARD, 1948; Hoshino and IWABUCHI, 1963).

The bay deepens fairly rapidly near the head down to $30-40 \mathrm{~m}$ and then gradually towards the mouth until the depth of $50 \mathrm{~m}$, as is well shown in Fig. 9a. On the contrary, off the coast of the two peninsulas the bay is remarkably deepened. Near the midpoint between Saganoseki and Muku-shima Island the depth contour of $60 \mathrm{~m}$ narrowly opens both to the north-northwest and to the south-southeast. In the area surrounded by the northernly opened depth contour of $60 \mathrm{~m}$, off the southeast-coast of Saganoseki Head, there is a submarine valley as deep as $90 \mathrm{~m}$. The central part, 10 to $60 \mathrm{~m}$ in depth, of the triangular bay is rather flat. No information is available about the tidal currents in Usuki Bay. 3. Sample location.-The samples examined were dredged by the use of a survey boat "Tsuru-maru" (5 tons) of Oita Fisheries Experimental Station, at the locations shown in Fig. 9a.

4. Bottom sediment.-The distribution of bottom sediments is shown in Fig. $9 \mathrm{~b}$. A rocky bottom which represents exposures of older rocks was nowhere found, as far as the present survey is concerned. According to the chart (No. 1218, JMSB), however, rocky bottoms, which are abbreviated as "Rock" in Fig. 9b, are recorded at some places. They are mainly distributed near the easternmost tip of the Saganoseki Peninsula, Tsuta-shima, Kuro-shima, Mitsugo-shima and Tsukumishima Islets. No gravel was found in the dredged samples, but the chart (No. 1218, JMSB) records the presence of gravels at some localities: south of the head of the Saganoseki Peninsula, north of Muku-shima and at the midpoint between the Kusuyasaki Headland and Muku-shima. 
Coarse sand is distributed between the head of the Saganoseki Peninsula and Muku-shima. Medium sand is mainly distributed in the central part of Usuki Bay and partly south of both Tsukumi-shima and Tsuta-shima. Fine sand is widely distributed in the bay mouth and partly south of Tsuta-shima Islet. Muddy sediments are distributed in the inner part of Usuki Bay. They consist of coarse and medium silts, the distribution of which is indicated respectively in Fig. 9b. Coarse silt is found in the main part of the inner Usuki Bay.

The variations of the textural composition of all of these sediments are shown on Table 1. Sedimentological data of the examined samples are shown on Table 1 and some results of their statistical analysis in Fig. 11.

\section{H. Tsukumi Bay}

1. Geographical position.-Tsukumi Bay is situated to the south of Usuki Bay in Oita Prefecture on the eastern side of middle Kyushu. Its approximate location is lat. $33^{\circ} 05^{\prime} \mathrm{N}$ and long. $135^{\circ} 55^{\prime} \mathrm{E}$ (Fig. 1).

2. Geomorphological feature.-Tsukumi Bay is separated from Usuki Bay by the Kusuyasaki Headland and from Saéki Bay by the Youra Headland. The bay faces to the Straits of Bungo-suido.

Tsukumi Bay is divided into two parts by the headland of Kannon-saki and is characterized by ria coasts. The bay is studded with small islands, of which Hoto-shima off the head of the Youra Peninsula and Okimuku-shima, off the head of Kusuyasaki are main ones. The submarine topography of Tsukumi Bay is complicated. The deepest caldron of about $95 \mathrm{~m}$ is located to the south of Jimukushima Island. A small submarine uplift, the top of which measures $29 \mathrm{~m}$ in depth, is found between the islands of Muku-shima and Hoto-shima. A submarine valley is traceable from the depth of $70 \mathrm{~m}$ to more than $120 \mathrm{~m}$ between the submarine uplift and Hoto-shima. It is extended into the Straits of Bungo-suido. Other minor submarine valleys are also recognizable in some large inlets of Tsukumi Bay, measuring from $20 \mathrm{~m}$ to $60 \mathrm{~m}$ in depth. A rather flat bottom may be seen at the depth of $30 \mathrm{~m}$ to $50 \mathrm{~m}$ in the main part of Tsukumi Bay, although it is not always clearly traceable. They should be compared with that in Usuki Bay. 3. Sample location.-Samples were dredged and collected by Oita Fisheries Experimental Station. Grid-sampling was made at $2 \mathrm{~km}$-interval and their locations are shown in Fig. 10a. As to the bottom sediments at the head of the bay, the data of the Maritime Safety Board were supplementarily used.

4. Bottom sediment.-The distribution of bottom sediments is shown in Fig. 10b. A rocky bottom is found near Muku-shima and Hoto-shima Islands and off the headland coasts.

Gravel is distributed only south of Muku-shima Island. Coarse sand is distributed between Muku-shima and Hoto-shima. Medium sand is distributed in the outermost area of Tsukumi Bay, while fine sand widely occupies the bay mouth and partly the bay head. Muddy sediments mainly composed of coarse silt are distributed near the coast of Tsukumi City and west of the Kannon-saki Headland. The textural variations of these sediments are shown in Fig. 12 and on Table 1. 


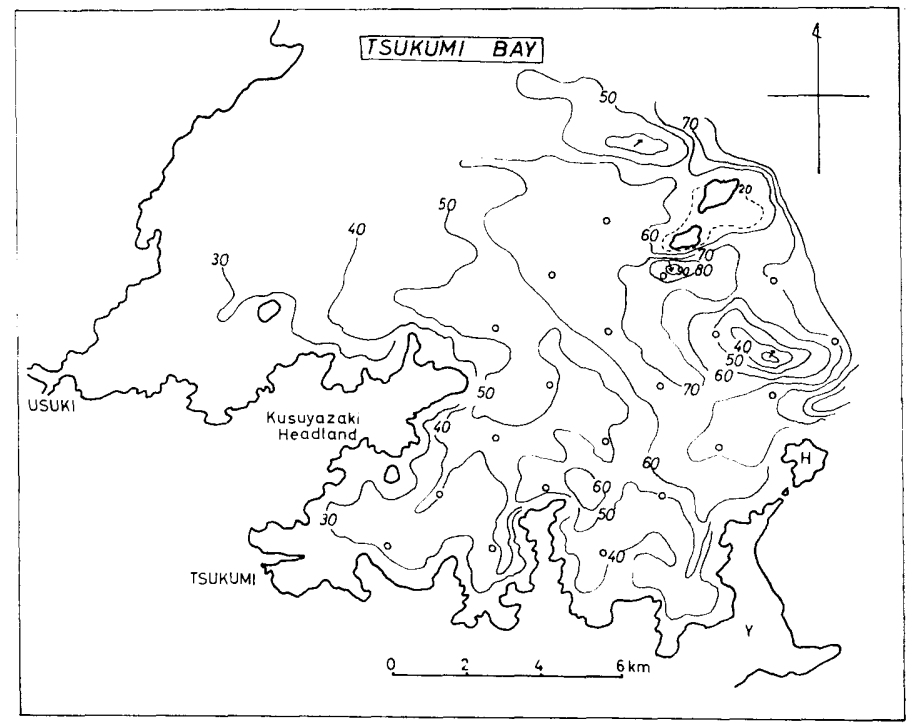

Fig. 10a. Sample locations and depth contours in Tsukumi Bay. Y: the Youra Headland; H: Hoto-shima Island

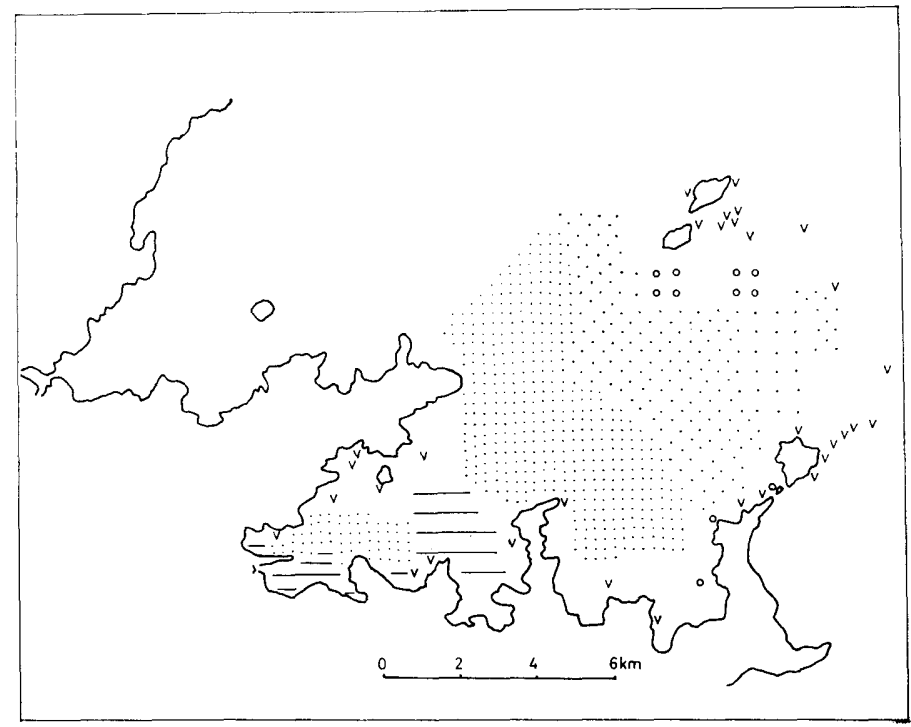

Fig. 10b. Distribution of bottom sediments in Tsukumi Bay.

Table 1. Textural variation of sediments in the selected bays of Kyushu.

Fukuoka Bay

\begin{tabular}{rlclcrrr} 
sediment & variation & Gravel & Sand & Mud & Md $\phi$ & $\sigma \phi$ & \multicolumn{1}{c}{$\alpha \phi$} \\
\hline Coarse & Max. & $52.0 \%$ & $96.9 \%$ & $18.0 \%$ & 0.90 & 2.83 & 0.36 \\
Sand & Min. & 3.1 & 57.0 & 0 & -0.16 & 0.90 & -0.10 \\
& Mean & 17.9 & 75.9 & 6.4 & 0.23 & 1.53 & 0.14
\end{tabular}




$\begin{array}{clrrrrrr}\text { Fine } & \text { Max. } & 11.1 & 98.8 & 29.9 & 3.23 & 1.90 & 0.25 \\ \text { Sand } & \text { Min. } & 0.3 & 59.0 & 0.1 & 2.15 & 0.63 & -0.19 \\ & \text { Mean } & 3.7 & 82.7 & 13.6 & 2.82 & 1.06 & -0.06 \\ \text { Coarse } & \text { Max. } & 12.0 & 48.0 & 77.0 & 5.00 & 2.43 & -0.01 \\ \text { Silt } & \text { Min. } & 0.5 & 16.0 & 51.0 & 4.03 & 1.49 & -0.42 \\ & \text { Mean } & 4.3 & 28.6 & 67.0 & 4.62 & 1.93 & -0.23 \\ \text { Medium } & \text { Max. } & 5.0 & 18.0 & 92.6 & 5.67 & 1.80 & 0.01 \\ \text { Silt } & \text { Min. } & 0.3 & 4.3 & 80.2 & 5.10 & 1.14 & -0.28 \\ & \text { Mean } & 2.2 & 10.6 & 87.1 & 5.40 & 1.28 & -0.04\end{array}$

Karatsu Bay

\begin{tabular}{|c|c|c|c|c|c|c|c|}
\hline sediment & variation & Gravel & Sand & Mud & $\mathrm{Md} \phi$ & $\sigma \phi$ & $\alpha \phi$ \\
\hline Coarse & Max. & $38.7 \%$ & $98.9 \%$ & $0.4 \%$ & 0.40 & 1.74 & 0.16 \\
\hline \multirow[t]{2}{*}{ Sand } & Min. & 1.1 & 60.9 & 0 & -0.53 & 0.51 & -0.11 \\
\hline & Mean & 15.2 & 84.6 & 0.01 & -0.05 & 0.86 & 0.01 \\
\hline Medium & Max. & 1.5 & 99.8 & 1.3 & 2.00 & 0.90 & 0.81 \\
\hline \multirow[t]{2}{*}{ Sand } & Min. & 0.1 & 97.3 & 0.1 & 1.22 & 0.43 & -0.12 \\
\hline & Mean & 0.9 & 98.5 & 0.5 & 1.72 & 0.70 & 0.02 \\
\hline Fine & Max. & 4.5 & 95.7 & 8.1 & 2.65 & 1.34 & -0.01 \\
\hline \multirow[t]{2}{*}{ Sand } & Min. & 0.7 & 87.6 & 1.9 & 2.55 & 0.76 & -0.25 \\
\hline & Mean & 2.4 & 93.4 & 3.8 & 2.59 & 0.98 & -0.15 \\
\hline
\end{tabular}

\section{Omura Bay}

\begin{tabular}{clcccccc} 
& & Gravel & Sand & Mud & Md $\phi$ & $\sigma \phi$ & $\alpha \phi$ \\
\hline Medium & Max. & $14.0 \%$ & $81.8 \%$ & $20.0 \%$ & 1.49 & 3.83 & 0.64 \\
Sand & Min. & 0.2 & 67.0 & 18.0 & 1.04 & 2.80 & 0.25 \\
& Mean & 4.8 & 76.2 & 19.0 & 1.26 & 3.17 & 0.49 \\
Fine & Max. & & & & & & \\
Sand & Min. & & & & & & \\
& Mean & 0 & 50.2 & 49.8 & 3.94 & 3.74 & 0.08 \\
Coarse & Max. & 0.9 & 39.9 & 65.6 & 4.65 & 2.64 & 0.05 \\
Silt & Min. & 0.6 & 33.8 & 59.5 & 4.30 & 1.04 & -0.19 \\
& Mean & 0.7 & 36.9 & 62.4 & 4.44 & 1.62 & -0.10 \\
Medium & Max. & 0.5 & 33.0 & 98.0 & 5.72 & 3.62 & 0.01 \\
Silt & Min. & 0.1 & 1.9 & 66.5 & 5.02 & 0.70 & -0.28 \\
& Mean & 0.3 & 17.5 & 82.2 & 5.37 & 1.98 & -0.14 \\
Fine & Max. & 2.0 & 20.9 & 99.6 & 7.69 & 3.56 & 0 \\
Silt & Min. & 0 & 0.4 & 79.0 & 6.15 & 1.01 & -0.47 \\
& Mean & 0.3 & 6.1 & 93.5 & 6.92 & 1.55 & -0.21
\end{tabular}

Arikawa Bay

\begin{tabular}{clcccccc} 
& & Gravel & Sand & Mud & Md $\phi$ & $\sigma \phi$ & $\alpha \sigma$ \\
\cline { 1 - 3 } Coarse & Max. & & & & & & \\
Sand & Min. & & & & & & \\
& Mean & $10.8 \%$ & $88.2 \%$ & $1.0 \%$ & 0.78 & 1.39 & -0.01 \\
Fine & Max. & 9.2 & 91.1 & 12.7 & 2.99 & 1.98 & -0.11 \\
Sand & Min. & 2.2 & 80.5 & 6.7 & 2.32 & 1.02 & -0.32 \\
& Mean & 4.8 & 85.3 & 9.7 & 2.62 & 1.49 & -0.23
\end{tabular}


Sakitsu Bay

\begin{tabular}{clcccrrr} 
sediment & variation & Gravel & Sand & Mud & Md $\phi$ & \multicolumn{1}{c}{$\sigma \phi$} & \multicolumn{1}{c}{$\alpha \phi$} \\
\hline Coarse & Max. & $45.0 \%$ & $72.0 \%$ & $23.0 \%$ & 0.13 & 3.35 & 0.55 \\
Sand & Min. & 27.8 & 32.0 & 0.2 & -0.68 & 1.43 & -0.18 \\
& Mean & 33.2 & 59.4 & 7.4 & -0.25 & 2.06 & 0.16 \\
Medium & Max. & 7.2 & 99.7 & 1.3 & 1.70 & 1.32 & 0.17 \\
Sand & Min. & 0.2 & 91.5 & 0.1 & 1.55 & 0.34 & -0.41 \\
& Mean & 3.2 & 96.0 & 0.8 & 1.60 & 0.75 & -0.07 \\
Fine & Max. & 14.0 & 99.7 & 42.9 & 2.80 & 2.91 & 0.10 \\
Sand & Min. & 0.2 & 49.5 & 0.1 & 2.18 & 0.45 & -0.16 \\
& Mean & 4.1 & 79.4 & 16.4 & 2.52 & 1.38 & -0.01 \\
Coarse & Max. & 27.0 & 31.5 & 71.1 & 4.78 & 4.21 & 0.03 \\
Silt & Min. & 0.9 & 1.9 & 63.6 & 4.48 & 1.43 & -0.67 \\
& Mean & 9.9 & 19.6 & 67.2 & 4.62 & 2.42 & -0.25 \\
Medium & Max. & 2.0 & 16.8 & 96.9 & 6.00 & 1.32 & 0.02 \\
Silt & Min. & 0 & 3.1 & 83.0 & 5.22 & 1.07 & -0.03 \\
& Mean & 0.3 & 6.6 & 93.2 & 5.73 & 1.11 & -0.01 \\
Fine & Max. & 1.0 & 2.2 & 98.9 & 6.29 & 1.05 & 0.01 \\
Silt & Min. & 0 & 1.1 & 97.6 & 6.09 & 0.99 & -0.02 \\
& Mean & 0.2 & 1.8 & 97.9 & 6.14 & 1.03 & -0.01
\end{tabular}

\section{Chijiwa Bay}

\begin{tabular}{clllrrrr} 
& & Gravel & Sand & Mud & Md $\phi$ & $\sigma \phi$ & $\alpha \phi$ \\
\hline \multirow{2}{*}{ Gravel } & Max. & $83.7 \%$ & $49.4 \%$ & $0.7 \%$ & -1.00 & 1.05 & 0.68 \\
& Min. & 50.0 & 16.0 & 0.2 & -2.12 & 0.72 & -0.07 \\
& Mean & 63.0 & 36.1 & 0.4 & -1.43 & 0.76 & 0.24 \\
Coarse & Max. & 43.5 & 89.6 & 11.6 & 0.81 & 2.25 & 0.38 \\
Sand & Min. & 10.2 & 10.2 & 0.2 & -0.34 & 0.91 & -0.03 \\
& Mean & 30.9 & 67.0 & 2.1 & 0.01 & 1.75 & -0.03 \\
Medium & Max. & 25.5 & 98.4 & 2.0 & 1.81 & 2.03 & -0.05 \\
Sand & Min. & 0.2 & 73.5 & 0.2 & 1.30 & 0.65 & -0.52 \\
& Mean & 6.6 & 92.0 & 1.1 & 1.59 & 1.07 & -0.21 \\
Fine & Max. & 4.4 & 98.6 & 49.6 & 3.97 & 1.49 & 0.43 \\
Sand & Min. & 0 & 50.0 & 0.4 & 2.12 & 0.35 & -0.29 \\
& Mean & 1.3 & 77.4 & 24.9 & 2.98 & 1.02 & 0.16 \\
Coarse & Max. & 8.0 & 48.0 & 76.0 & 4.97 & 1.93 & 0.39 \\
Silt & Min. & 0 & 23.6 & 52.0 & 4.07 & 1.13 & -0.02 \\
& Mean & 0.4 & 38.4 & 54.9 & 4.04 & 1.23 & 0.06 \\
Medium & Max. & 0.4 & 18.2 & 96.0 & 5.89 & 1.19 & 0.01 \\
Silt & Min. & 0 & 4.0 & 81.8 & 5.17 & 1.10 & -0.02 \\
& Mean & 0.1 & 8.3 & 91.7 & 5.65 & 1.17 & 0 \\
Fine & Max. & 0.4 & 2.5 & 98.9 & 6.27 & 1.05 & 0 \\
Silt & Min. & 0.1 & 1.1 & 97.5 & 6.02 & 1.06 & -0.03 \\
& Mean & 0.2 & 1.7 & 98.3 & 6.15 & 1.02 & -0.01
\end{tabular}

Usuki Bay

\begin{tabular}{rlllllll} 
& & Gravel & Sand & Mud & Md $\phi$ & $\sigma \phi$ & $\alpha \phi$ \\
\hline Coarse & Max. & $28.6 \%$ & $71.4 \%$ & $17.9 \%$ & 0.82 & 3.00 & -0.11 \\
Sand & Min. & 28.3 & 50.5 & 0.3 & 0.14 & 1.66 & -0.30 \\
& Mean & 28.5 & 61.0 & 8.1 & 0.48 & 2.33 & -0.21
\end{tabular}




\begin{tabular}{clrlrrrr} 
Medium & Max. & 31.8 & 96.8 & 13.8 & 1.92 & 2.15 & 0.02 \\
Sand & Min. & 3.8 & 68.2 & 0 & 1.03 & 0.88 & -0.66 \\
& Mean & 13.5 & 83.2 & 3.8 & 1.63 & 1.37 & -0.29 \\
Fine & Max. & 12.0 & 97.3 & 50.0 & 4.00 & 2.17 & 0.47 \\
Sand & Min. & 0.4 & 49.6 & 1.3 & 2.07 & 0.46 & -0.33 \\
& Mean & 2.7 & 77.6 & 17.9 & 2.97 & 1.04 & 0.33 \\
Coarse & Max. & 1.4 & 42.0 & 63.2 & 4.50 & 1.48 & 0.19 \\
Silt & Min. & 0.8 & 36.0 & 56.6 & 4.25 & 1.29 & 0 \\
& Mean & 1.10 & 39.0 & 59.9 & 4.35 & 1.39 & 0.10 \\
Medium & Max. & & & & & & \\
Silt & Min. & & & & & & \\
& Mean & 0.4 & 15.4 & 84.2 & 5.29 & 1.26 & -0.11 \\
& & & & & & & \\
& & & Tsukumi & Bay & & & \\
sediment & variation & Gravel & Sand & Mud & Md $\phi$ & $\sigma \phi$ & $\alpha \phi$ \\
\hline Gravel & Max. & $59.7 \%$ & $42.4 \%$ & $0.3 \%$ & -1.42 & 1.83 & 0.99 \\
& Min. & 57.3 & 40.1 & 0.2 & -1.78 & 1.73 & 0.71 \\
& Mean & 58.5 & 41.2 & 0.25 & -1.60 & 1.78 & 0.85 \\
Coarse & Max. & & & & & & \\
Sand & Min. & & & & & & \\
& Mean & 21.9 & 77.8 & 0.3 & -0.01 & 1.44 & 0 \\
Medium & Max. & 29.7 & 87.4 & 1.6 & 1.98 & 1.89 & -0.31 \\
Sand & Min. & 11.8 & 70.0 & 0.2 & 1.02 & 1.17 & -0.66 \\
& Mean & 18.0 & 81.4 & 0.6 & 1.41 & 1.61 & -0.54 \\
Fine & Max. & 4.3 & 98.3 & 40.2 & 3.79 & 1.22 & 0.37 \\
Sand & Min. & 0.2 & 58.8 & 0.4 & 2.10 & 0.44 & -0.46 \\
& Mean & 2.0 & 85.5 & 12.5 & 2.93 & 0.76 & -0.01 \\
Coarse & Max. & 0.8 & 37.2 & 62.0 & 4.47 & 1.35 & 0.12 \\
Silt & Min. & 0.6 & 30.4 & 60.0 & 4.38 & 1.32 & 0.11 \\
& Mean & 0.7 & 33.8 & 61.0 & 4.42 & 1.33 & 0.11
\end{tabular}

\section{Concluding remarks}

In this chapter the distribution of bottom sediments in the bays of North Kyushu is generally discussed. Before doing so the writer attempts to classify the environments of bays.

1. Degree of embayments.-As has been briefly described in the Introduction, the surveyed bays may be arranged as follows from a closed bay to an opened one according to the degree of embayment. The ratio of the elongation (B) of a bay to the width of a bay mouth (A), as shown in the right column, may roughly, if not accurately, indicates the degree of embayment.

$\begin{array}{lccc}\text { bay } & \text { width in } \mathrm{km}(\mathrm{A}) & \text { length in } \mathrm{km}(\mathrm{B}) & \mathrm{B} / \mathrm{A} \\ \text { Omura } & 0.5 & 27.5 & 55.0 \\ \text { Sakitsu } & 2.5 & 7.0 & 2.8 \\ \text { Fukuoka } & 5.7 & 13.2 & 2.3 \\ \text { Arikawa } & 7.0 & 7.0 & 1.0 \\ \text { Usuki } & 11.3 & 10.5 & 0.9 \\ \text { Tsukumi } & 8.9 & 8.7 & 0.9 \\ \text { Karatsu } & 14.4 & 12.0 & 0.8 \\ \text { Chijiwa } & 36.5 & 30.0 & 0.8\end{array}$


This order generally agrees with that of predominance of finer sediments. In other words, a bay with higher degree of embayment has more muddy sediments. The opened Chijiwa Bay may be exceptional in that muddy sediments are considerably found in its innermost part because of special conditions.

2. Sedimentary environment of bays.-Hoshino (1958) discussed on a sedimentary environment of bays in the Japanese Islands and divided it into four: estuarine, coastal, bay mouth and bay center. The estuary is a tidal mouth of large rivers, which however, is not always existent in a bay nor confined to a bay. It is another environment. Therefore, the writer has modified HosHino's classification as follows: bay-head, bay-center, bay-mouth and coastal environments. They can be furthermore subdivided by other conditions such as the topography and geology of coasts and backgrounds, existence or absence of large rivers flowing into the bay, etc.

(1) Bay-mouth environment: A sandy facies characterizes this environment without exception. Near the entrance of the closed bay of Omura, where the tidal flow runs strongly, a rocky bottom is exposed and in Chijiwa Bay gravel is subordinately found.

(2) Bay-center environment: The sedimentary facies in this environment seems to be related to the degree of embayment of bays. Bays with a large degree of embayment, such as Fukuoka, Sakitsu and Omura Bays, have muddy sediments, while bays with a small degree of embayment, such as Arikawa, Usuki and Chijiwa Bay, have sandy to even gravelly sediments in the central area. Sakitsu and Tsukumi Bays are so complicated in topography that their sedimentary facies are also exceptionally complex.

(3) Bay-head environment: This is characterized by muddy facies, as seen in most of the surveyed bays. An exception is Karatsu Bay, where the bayhead environment is mainly occupied by sandy sediments with subordinate mud.

(4) Coastal environment: Generally this environment is characterized either by rocky bottom or by sediments of gravelly sands.

3. Distribution of principal bottom types.-As has already been described in the foregoing chapters, principal types of bottom of bays are classified into the rock, gravel, sand and mud bottoms. Conditions favourable for these bottoms are respectively generalized as follows:

A rocky bottom is found commonly (1) at bay mouths, (2) along coasts of islands and the main land, and (3) in submarine channels.

A sand bottom, which is the most common type, is generally found (1) off coasts of the main land, (2) at bay mouths, and (3) in the central area of some bays.

A muddy bottom, which is also very common type, is dominant (1) in the central area of bays, (2) in bay-head areas, and (3) in areas of slight depression.

4. Interrelations between grain size parameters.-Interrelations between the grain size parameters of median diameter, sorting coefficient and skewness are summarized in Fig. 11. The best size sorting is in a limited grade between 2 and $3 \mathrm{phi}$, and becomes progressively poorer toward both coarser and finer grades, 
forming a V-shaped trend. This trend remarkably agrees with a part of that first presented by FoLK and WARD (1957) in their study of the Brazos River bar, Texas. According to them, when the sedimentary detritus consists of two or more grades, a roughly sinusoidal or M-shaped trend (or part of the trend) exists between mean grain size and size sorting. This trend, or a part of the trend, has been reported in sediments, either ancient or modern, from the Upper Cretaceous Carpatian Flysch (UNRUG, 1962), modern sediments in the Red Sea (SHUKRI and HIGAzY, 1944), Tertiary sediments in the Caribbean area (GRIFFITH, 1964), modern deep-sea sediments in the western Atlantic (HUBERT, 1964) and
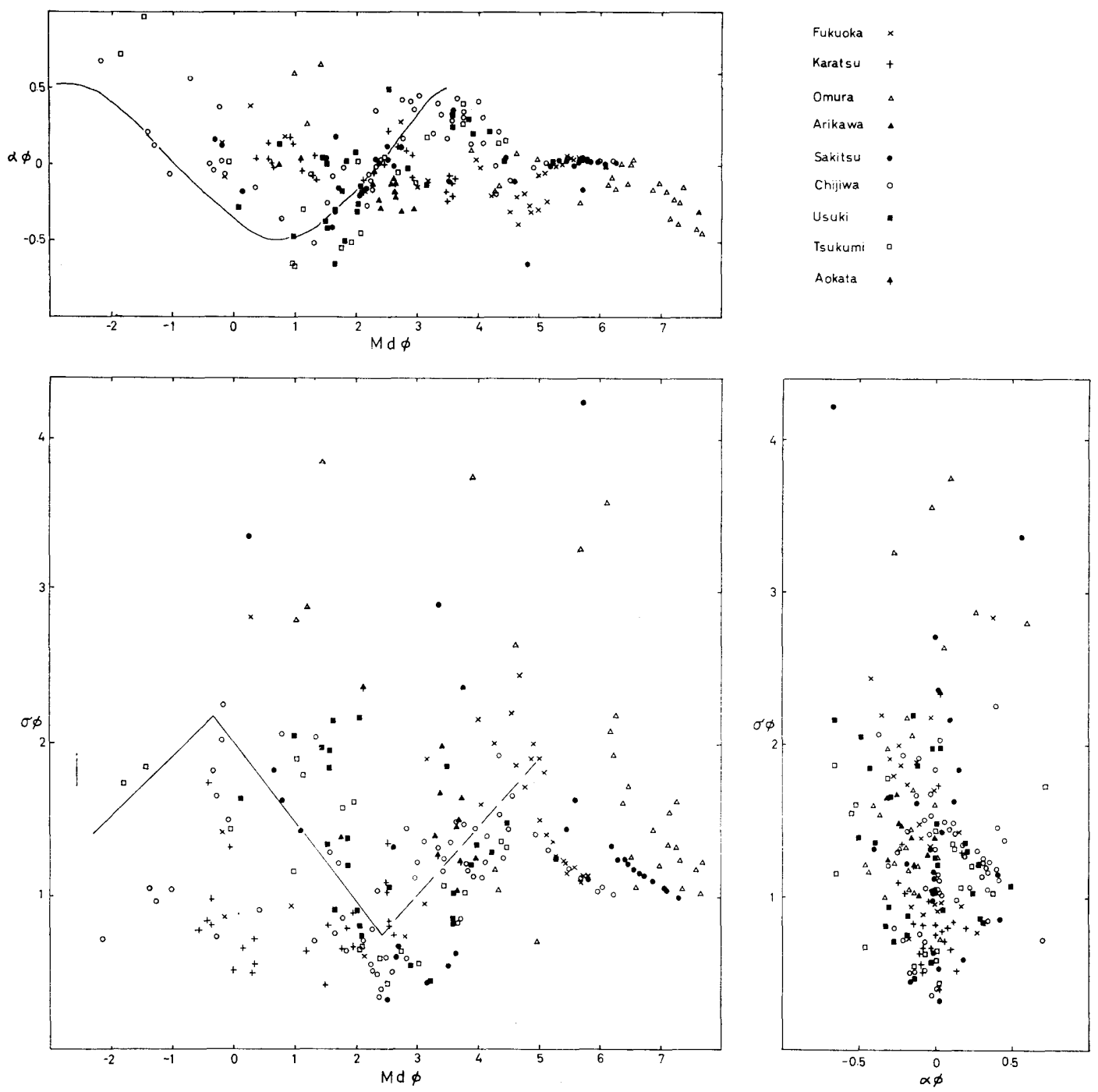

Fig. 11. Compiled relation among $\mathrm{Md} \phi, \sigma \phi$ and $\alpha \phi$ in the surveyed bays.

The reference line is cited from Folk et al. (1957).

Aokata* is not a bay, but an opened sea-area.

* Aokata is located at the west of Arikawa Bay. 
Lower Paleozoic sediments from the Welsh geosyncline (OKADA, in press).

A typical sinusoidal relationship is also present between mean size and skewness (Fig. 11). The present study indicates that the maximum coarse skewness occurs near the grades of very coarse sand, very fine sand and medium to fine silt, while minimum fine skewness occurs near the grades of medium sand and coarse silt. This result fairly well agrees with that of FoLK et al. (1957).

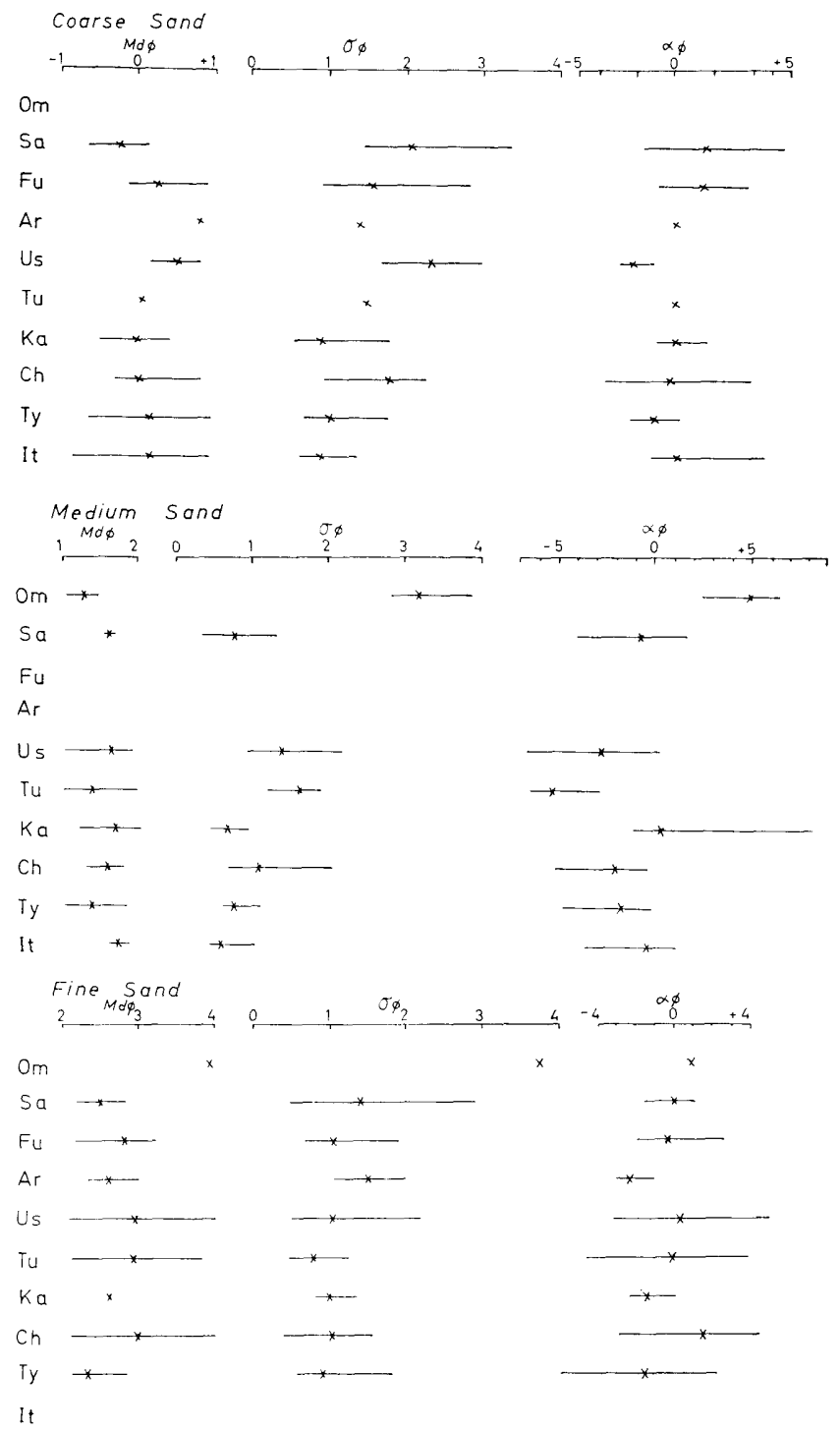

Fig. 12. Textural variation of sands in the surveyed bay and non-bay area.

Ty: off Tsuyazaki; It: off the Itoshima Peninsula. Other letters on the left side are reffered to the bay-names mentioned on Page 28 of Chapter IV. A line and symbol X respectively show the range and the average of grain size parameter. 
As to sorting coefficient versus skewness, no definite relationship is drawn out from the available data (Fig. 11). FoLK et al. (1957), however, showed a circular trend between the two parameters.

5. Comparison with sediments off some shores without embayment.-It seems pertinent to compare the features of bottom sediments in bays with those of sediments off the shores without embayment, here simply called the non-bay sediments. The writer is going to refer here results of his previous study on the bottom sediments off Tsuyazaki, northeast of Fukuoka City, and off the Itoshima Peninsula between Fukuoka and Karatsu (Mitsushio, 1965a and b).

As regards physiographical conditions of these selected areas, the Tsuyazaki sea-area is somewhat enclosed by three islands on the offshore side, presenting, so to speak, a semiclosed sea-area, whereas the Itoshima sea-area, which has no islands, is a thoroughly opened one. The former is characterized by two submarine terraces of different levels: $10-20 \mathrm{~m}$ and over $35 \mathrm{~m}$ in depth, respectively (Mitsushio, 1965a). The constant current in the area is a northeasterly flow with about 0.2 knot. The latter has a submerged headland at the depth of 25 to $30 \mathrm{~m}$, which protrudes northwards at the Nogita, Itoshima Peninsula (Mitsushio, $1965 \mathrm{~b})$. The tidal flows there run from the southwest to the northeast at about 0.6 knot at the high tide and from the northeast to the southwest at about 0.4 knot at the low tide.

The sediments of these areas consist of gravel and sand, and in some parts there are exposures of rocky bottom. Muddy sediments are hardly found. According to Hoshino (1952, 1958), however, muddy sediments can occur in the area along the frontal line of current rip even in an open sea. No examples of such a case have been found in the surveyed areas. Both the tidal currents and the constant ones are too strong there to deposit muddy sediments.

Gravel is found in the Tsuyazaki sea-area, but is not found in the Itoshima sea-area. The textural variation of the gravel off Tsuyazaki is as follows:

$\begin{array}{cccccc}\begin{array}{c}\text { gravel } \\ \text { content }\end{array} & \begin{array}{c}\text { sand } \\ \text { content }\end{array} & \begin{array}{c}\text { mud } \\ \text { content }\end{array} & \mathrm{Md} \phi & \sigma \phi & \alpha \phi \\ 53.4 \% & 46.4 \% & 0.2 \% & -0.12 & 1.23 & -0.49\end{array}$

The gravel off Tsuyazaki is finer in median diameter and more finely skewed than that of the bays of Chijiwa and Tsukumi.

The average textural variation of the examined sandy sediments off the shores without embayment is as follows:

\begin{tabular}{|c|c|c|c|c|c|c|c|}
\hline & & $\begin{array}{c}\text { gravel } \\
\text { content } \\
\%\end{array}$ & $\begin{array}{c}\text { sand } \\
\text { content } \\
\%\end{array}$ & $\underset{\text { content }}{\operatorname{mud}}$ & $\mathrm{Md} \phi$ & $\sigma \phi$ & $\alpha \phi$ \\
\hline \multirow{3}{*}{$\begin{array}{l}\text { Off } \\
\text { Tsuyazaki }\end{array}$} & coarse sand & 19.5 & 80.4 & 0.1 & 0.12 & 0.98 & -0.10 \\
\hline & medium sand & 4.5 & 95.0 & 0.5 & 1.37 & 0.74 & -0.18 \\
\hline & fine sand & 3.7 & 93.0 & 3.3 & 2.33 & 0.88 & -0.15 \\
\hline \multirow{2}{*}{$\begin{array}{l}\text { Off } \\
\text { Itoshima }\end{array}$} & coarse sand & 9.2 & 90.7 & 0.1 & 0.15 & 0.81 & 0.01 \\
\hline & medium sand & 0.9 & 99.0 & 0.1 & 1.73 & 0.53 & -0.04 \\
\hline
\end{tabular}

As is indicated in Fig. 12, the coarse and medium sands of the two areas are 
nearly equal in median diameter and better sorted than those of the opened bays of Tsukumi, Karatsu and Chijiwa Bays. The fine sand off Tsuyazaki, which is not found off the Itoshima Peninsula, is coarser, better sorted and more coarsely skewed than that of the bay sediments. Mud is not found at all in the sediments off Tsuyazaki and off the Itoshima Peninsula.

To sum up, the sorting of sands is generally better in the non-bay sediments than in the bay sediments. A remarkable difference between them is that mud is not found in the examined non-bay sediments, but is a common constituent in the bay sediments. An interesting trend is that many statistical parameters of the non-bay sediments are very similar to those of the opened bay sediments and different from those of the closed bay sediments.

\section{References Cited}

Ariake Bay Research Group (1965): Quaternary system of the Ariake and the Shiranuhi Bay areas, with special reference to the Ariake Soft Clay (in Japanese with English abstract). Assoc. Geol. Collab. Japan, monograph, 11, 1-86.

FoLK, R. L. and WARD, W. C. (1957): Brazos river bar: a study in the significance of grain size parameters. Jour. Sed. Petr., 27, (1), 3-26.

GRIFFITH, J. C. (1951) : Size versus sorting in some Caribbean sediments. Jour. Geol., 59, 211-243.

Hoshino, Michihei (1952): On the muddy sediments of the adjacent to Japan (in Japanese with English abstract). Jour. Geol. Soc. Japan, 58, (677), 41-53. (1958): The shelf sediments in the adjacent seas of Japan (in Japanese with English abstract). Assoc. Geol. Collab. Japan, monograph, 7, 1-41.

and IWABUCHI, Yoshiro (1963): Some problems on the formation of the Seto Inland Sea, Japan-the case of the Nabeshima-suido (in Japanese with English abstract). Jour. Geol. Soc. Japan, 69, (810), 147-156.

HUberT, J. H. (1964): Textural evidence for deposition of many western north Atlantic deep-sea sands by ocean-bottom currents rather than turbidity currents. Jour. Geol., 72, 757-785.

Hydrographic Offices, Japan Maritime Safety Board (1959): Submarine topography, distribution of bottom sediments and tidal currents in the Shimabara Inland Sea (in Japanese). Rep. Res. Hydrogr. Off., 1-26.

(1959): Results of analysis of the bottom sediments lately dredged (in Japanese with English abstract). Rep. Hydrogr. Off., 39-48.

INMAN, D. L. (1952): Measures for describing the size distribution of sediments. Jour. Sed. Petr. 22, (3), 125-145.

Inoué, Eiji (1954): Bottom sediments in Omura Bay (in Japanese). Rep. Omura Bay Res. [Mimeograph], Nagasaki Prefecture Fisheries Experimental Station, $1-15$.

Kamata, Yasuhiko (1957): Bottom sediment in the Ariake Inland Sea (short note, in Japanese). Taisekigaku-kenkyu (Sedimentological Research), (16), 5-8. (1959): Submarine geology of Aba Bay, the environs of Nagasaki City, Kyushu-Study on the Yamagi Coal-field. Part 2 (in Japanese with English abstract). Sci. Bull. Fac. Lib. Arts Educ., Nagasaki Univ., (14), 33-47.

(1964): Bottom sediments and molluscan remains of Nagasaki Bay (in Japanese). Sci. Bull. Fac. Lib. Arts Educ., Nagasaki Univ., (15), 97-104.

and Horiguchi, Yoshiaki (1963): Bottom sediments and shell remains from Mogi Area in Chijiwa Bay, Kyushu (in Japanese with English abstract). Sci. 
Bull. Fac. Lib. Arts Educ., Nagasaki Univ., (14), 33-47.

Krumbein, W. C. (1934): Size frequency distribution of sediments. Jour. Sed. Petr. 4, 65-77.

and Pettijohn, F. T. (1938): Manual of sedimentary petrography. 1-549, Appleton-Century-Crafts, New York.

and Sloss, L. L. (1953): Stratigraphy and sedimentation. 1-497, W. H. Freeman Co., Sanfrancisco.

Matsurshi, Hideyuki (1966): Genesis of the marine iron sand deposits in the Alluvium sediment, Ariake Bay (in Japanese with English abstract). Jour. Min. Inst. Kyushu, 34, (1), 23-60.

Matsumoto, Tatsuro, Noda, Mitsuo and MiYahisa, Michitoshi (1962): Kyushu, Regional Geology of Japan (in Japanese). 1-423, Asakura Book Co., Tokyo.

Mitsushio, Hiromi (1964): Bottom sediments near the Tomioka Peninsula, Amakusa, Kumamoto Prefecture, Kyushu, Japan (in Japanese with English abstract). Sci. Rep., Fac. Sci., Kyushu Univ., Ser. Geol., 6, (3), 167-187.

(1965a): Bottom sediments off the Itoshima Peninsula, Fukuoka Prefecture (in Japanese with English abstract). Sci. Rep. Fac. Sci. Kyushu Univ., Ser. Geol., 8, (1), 63-72.

(1965b) : Bottom sediments off Tsuyazaki, northeast of Fukuoka City (in Japanese with English abstract). Sci. Rep. Fac. Sci., Kyushu Univ., Ser. Geol., $8,(2), 101-124$.

Nagasaki Marine Meteorological Observatory (1954): Oceanographical study of the Ariake Inland Sea in relation to the comprehensive exploitation project (1). [Mimeograph], 1-76.

NASU, Noriyuki (1956): Particle size distribution in the vicinity off Sagami River mouth (The process forming beach and dune sands). Jour. Fac. Sci. Univ. Tokyo, 10, (I), 65-108.

OKADA, Hakuyu (in press): Non-greywacke "turbidite" sandstones in the Welsh geosyncline. Sedimentology.

SATo, Takahiro and NASU, Noriyuki (1956): Mechanical analysis of muddy sediments (especially on the pipette method) (in Japanese). Taisekigaku-kenkyu (Sedimentological research), (13), 6-9.

ShePARD, F. P. (1948): Submarine geology. 1-348. Harper \& Brothers, New York.

ShUKRI, N. M. and HigazY, R. A. (1944) : Mechanical analysis of some bottom deposits of the northern Red Sea. Jour. Sed. Petr., 14, 43-69.

Shuto, Tsugio (1953): A study on the foraminiferal assemblage of Omura Bay, Nagasaki Prefecture, Kyushu. Japan. Jour. Geol. Geogr., 23, 127-138.

Twenhofed, W. H. and TYler, S. A. (1941): Methods of study of sediments. 1-183, McGraw-Hill Book Co., N.Y. and London.

UNRUG, R. (1963) : Istebna Beds-a fluxoturbidite formation in the Carpathian flysch. Ann. Soc. Géol. Pologne, 33, 49-92. 